\title{
Epigenetics in ovarian cancer: premise, properties, and perspectives
}

\author{
Qilian Yang ${ }^{1 \dagger}$, Yuqing Yang ${ }^{2 \dagger}$, Nianxin Zhou ${ }^{1 \dagger}$, Kexin Tang ${ }^{3 \dagger}$, Wayne Bond Lau ${ }^{4}$, Bonnie Lau ${ }^{5}$, Wei Wang ${ }^{6}$, Lian Xu', \\ Zhengnan Yang ${ }^{1}$, Shuang Huang ${ }^{1}$, Xin Wang ${ }^{6}$, Tao Yi ${ }^{1}$, Xia Zhao ${ }^{1}$, Yuquan Wei ${ }^{1}$, Hongjing Wang ${ }^{1 *}$, \\ Linjie Zhao ${ }^{1 *}$ and Shengtao Zhou ${ }^{1 *}$
}

\begin{abstract}
Malignant ovarian tumors bear the highest mortality rate among all gynecological cancers. Both late tumor diagnosis and tolerance to available chemical therapy increase patient mortality. Therefore, it is both urgent and important to identify biomarkers facilitating early identification and novel agents preventing recurrence. Accumulating evidence demonstrates that epigenetic aberrations (particularly histone modifications) are crucial in tumor initiation and development. Histone acetylation and methylation are respectively regulated by acetyltransferases-deacetylases and methyltransferases-demethylases, both of which are implicated in ovarian cancer pathogenesis. In this review, we summarize the most recent discoveries pertaining to ovarian cancer development arising from the imbalance of histone acetylation and methylation, and provide insight into novel therapeutic interventions for the treatment of ovarian carcinoma.
\end{abstract}

Keywords: Ovarian cancer, Epigenetics, Histone methylaiton, Histone acetylation

\section{Background}

Malignant ovarian tumor has the highest mortality rate among all gynecological cancers [1]. Epithelial ovarian cancer (EOC) is the most common type of ovarian cancer [2]. In general, the majority of EOC patients are diagnosed in advanced stage (Stage III or IV) disease, due to the non-specific symptoms characteristic of early stage EOC and the lack of available EOC-specific screening biomarkers. Standard EOC therapy consists of debulking surgery followed by platinum-based chemical therapy $[3,4]$. While the initial tumor response is frequently promising, unfortunately, tumors recur rapidly due to chemo-resistance. Acquired chemo-resistance is a daunting challenge in EOC treatment [5]. Thus, the identification of novel cancer-specific biomarkers capable of detecting early

\footnotetext{
*Correspondence: whiscdx@163.com; ljzhao89@163.com;

taotaovip2005@163.com

${ }^{+}$Qilian Yang, Yuqing Yang, Nianxin Zhou and Kexin Tang contributed equally to this work.

${ }^{1}$ Department of Obstetrics and Gynecology, Key Laboratory of Birth Defects and Related Diseases of Women and Children of MOE and State Key Laboratory of Biotherapy, West China Second University Hospital, Sichuan University and Collaborative Innovation Center, Chengdu 610041, People's Republic of China

Full list of author information is available at the end of the article
}

stage disease, as well as efficient therapeutic agents against EOC recurrence, is vital for EOC treatment.

The genesis of cancer lies within gene alteration [6]. However, epigenetics (the phenotypic alteration in gene expression without modification of the DNA sequence itself) has increasingly been recognized for its role in tumor formation. Recently, a series of cancer-associated genes, regulated by epigenetic modification, has been implicated in the onset and progression of malignant ovarian tumor [7]. Epigenetics includes DNA methylation, nucleosome repositioning, histone post-translational modification, and post-transcriptional gene regulation by miRNAs [8]. Specifically, histone modification, regulated by histone modifying enzymes, manipulates gene expression $[9,10]$. Histone modification alters chromatin structure, and is heritable, passing to daughter cell generations. The basic building blocks of chromatin, each nucleosome harbors an octameric core, assembled by two copies of each histone ( $\mathrm{H} 2 \mathrm{~A}, \mathrm{H} 2 \mathrm{~B}, \mathrm{H} 3$, and $\mathrm{H} 4)$ protein wrapped by 145-147 DNA base pairs (bp). The linker histone $\mathrm{H} 1$ binds nucleosomes together, which fold into higherorder chromatin structures [11]. The amino-terminal tails of histones are flexible and unstructured, capable of directly altering the structure of chromatin and 
ultimately affecting gene expression via enzyme modification. Histone modification dynamically maintains the steady state of chromatin. At least eight different histone modifications exist: acetylation, methylation, phosphorylation, ubiquitination, glycosylation, sumoylation, ADPribosylation, and carbonylation [12, 13]. The balance of histone acetylation and methylation is respectively controlled by histone acetyltransferases-deacetylases and histone methyltransferases-demethylases. Disruption of the steady state may cause abnormal cellular function, possibly even ovarian cancer (Fig. 1) [14, 15].

\section{Potential biomarkers of histone modifications for ovarian cancer}

Decades of study have detected a variety of biomarkers for diagnosis and prognosis of ovarian cancer. The most widely used is the biomarker CA125 (also known as mucin 16). The CA125 blood test is not an effective screening test when used alone, given that CA125 levels are only increased in 50\% of stage I ovarian cancers and can also be increased in benign disorders, such as uterine fibroids, ovarian cysts and other conditions such as liver disease and infections $[16,17]$. Increased levels of CA125 are most

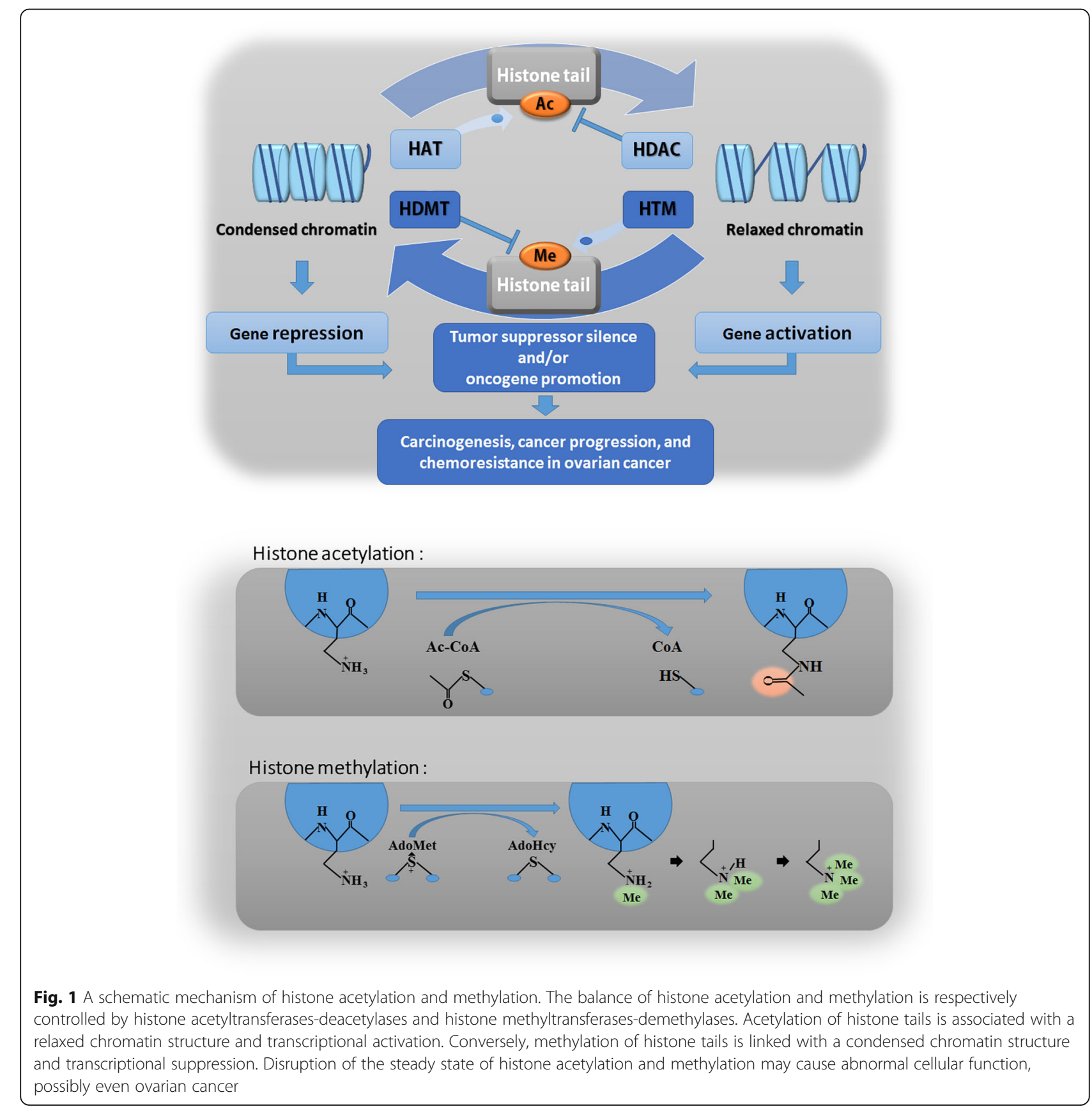


frequently observed in high grade serous carcinoma(HGSC), with lower levels of CA125 in other non-serous subtypes. The combination of the CA125 blood test and radiographic imaging, such as transvaginal ultrasonography, has been evaluated for use as a screening strategy. One of the largest studies to examine this combination was the PLCO Cancer Screening trial, which enrolled 78,216 women $55-74$ years of age [18]. Ovarian cancer was diagnosed in 212 women (5.7 per 10,000 person-years) in the screening group and in 176 women (4.7 per 10,000 person-years) in the usual care group (rate ratio: $1.21 ; 95 \% \mathrm{CI}: 0.99-1.48$ ), and the stage distributions of cancer were similar for the two groups (stage III and stage IV cancers comprised almost $80 \%$ of cancers in both groups). Although the CA125 test alone as a screening marker has been considered ineffective, the UKCTOCS study evaluated longitudinal measurements of CA125 levels for the screening of ovarian cancer in an algorithm termed 'risk of ovarian cancer algorithm' (ROCA) [19]. The mortality reduction was not significant between any of the research groups in this trial and thus, the ROCA test cannot currently be recommended as a screening strategy for ovarian cancer; further follow-up of this study is necessary to understand the long-term potential of this screening strategy. Another ovarian cancer biomarker is human epididymis protein 4 (HE4; also known as WFDC2) [20]. A systematic review reported better sensitivity, specificity and likelihood ratios for HE4 compared with CA125, but this has not yet been analysed within a screening strategy [21]. The use of other novel markers for ovarian cancer screening are under investigation, including, for example, DNA analysis of uterine lavages or Pap smears for TP53 mutations [22]. In this sense, currently none of these biomarkers could be used as an exact index for diagnosis and prognosis prediction of ovarian cancer patients due to the lack of sensitivity and specificity. Despite the mechanisms of how these histone modification alterations arise in ovarian cancer remain unclear, the fact that aberrant histone modification occurs frequently in malignant ovarian tumors and are thought to contribute both to the initiation and development of ovarian cancer. Hence, the exploration of histone modification holds great promise in revealing attractive biomarkers for diagnosis, prognosis and therapeutic targets in women with malignant ovarian tumors.

\section{Histone acetylation}

In general, histone acetylation relates to the relaxed chromatin state, which facilitates gene transcription. The overall level of histone acetylation is a dynamic process, controlled by two opposing enzymes: histone acetyltransferases (HATs) and histone deacetylases (HDACs) [23]. These enzymes have a profound effect upon the structure of chromatin. Imbalance between HATs and HDACs contributes to the pathogenesis of ovarian cancer [15].

\section{Histone acetyltransferases (HATs)}

Utilizing acetyl coenzyme A (acetyl-CoA) as a common acetyl donor, HATs catalyze the transfer of the acetyl group to the $\varepsilon$-amino group of lysine side chains. This action directly abolishes the positive charge of lysine, eliminating the electrostatic bond between DNA and histone [23]. HATs, therefore, unfold the local chromatin structure, rendering it more accessible to non-chromatin proteins.

\section{Classification and biology of HATs}

Two major HAT types exist: nuclear (A-type) and cytoplasmic (B-type) (Fig. 2) [24]. Type-A HATs are categorized by structural homologies and functional similarities into three subfamilies: the MYST (Moz-Ybf2/Sas3-Sas2Tip60) family, the GCN5-related N-acetyltransferases (GNAT) family and the p300/CREB-binding protein (CBP/CREBBP) family. The MYST family contains a specific sequence region (called MYST domain), made of an acetyl-CoA binding motif and a zinc finger. Some MYST family members also possess additional structural features termed chromo-domains (MOF, Esa1, and Tip60) [25]. The GNAT enzyme superfamily is widespread in nature [26]. In spite of substrate diversity, GNAT superfamily members are generally characterized by a highly conserved GNAT domain (composed of 6-7 anti-parallel $\beta$-strands and $4 \alpha$-helices in the topology $\beta 1-\alpha 1-\alpha 2$ $\beta 2-\beta 3-\beta 4-\alpha 3-\beta 5-\alpha 4-\beta 6-\beta 7 \quad[26,27])$, and can acetylate lysine residues on histones $\mathrm{H} 2 \mathrm{~B}, \mathrm{H} 3$, and $\mathrm{H} 4$. GNAT domain contains three conserved motifs in the order of D-A-B. Motifs A and B are highly conserved, and participate in acyl-CoA and acceptor substrate recognition and binding. Motifs D preserves the stable state of these proteins. Some other members of GNAT family harbor another conserved motifs $\mathrm{C}$ that is located at the N-terminus of these proteins [27, 28]. Although the structure of p300/CBP family has not yet been fully elucidated, several studies have shown that the structure and the catalytic mechanism of this group of proteins are obviously distinct from the MYST and GNAT families [29]. Except for a large HAT domain (about 500 residues) and a bromodomain, most importantly, the p300/CBP family possesses three putative zinc finger domains ( $\mathrm{ZZ}$, PHD and TAZ) that mediate protein-protein interaction, as well as two protease-resistant domains connected by a long protease-sensitive loop, which are not seen in other HAT members [28-30]. Moreover, it has been observed that the p300/CBP family employs a Theorell-Chance, or "hit" and "run" mechanism which differ from the mechanism of GNAT proteins (a sequential mechanism) and MYST proteins (a ping pong mechanism) [29]. Hat1 (histone acetyltransferase 1), which was the first histone acetyltransferase identified, is the only representative member of B-type HATs [31]. This enzyme is primarily 


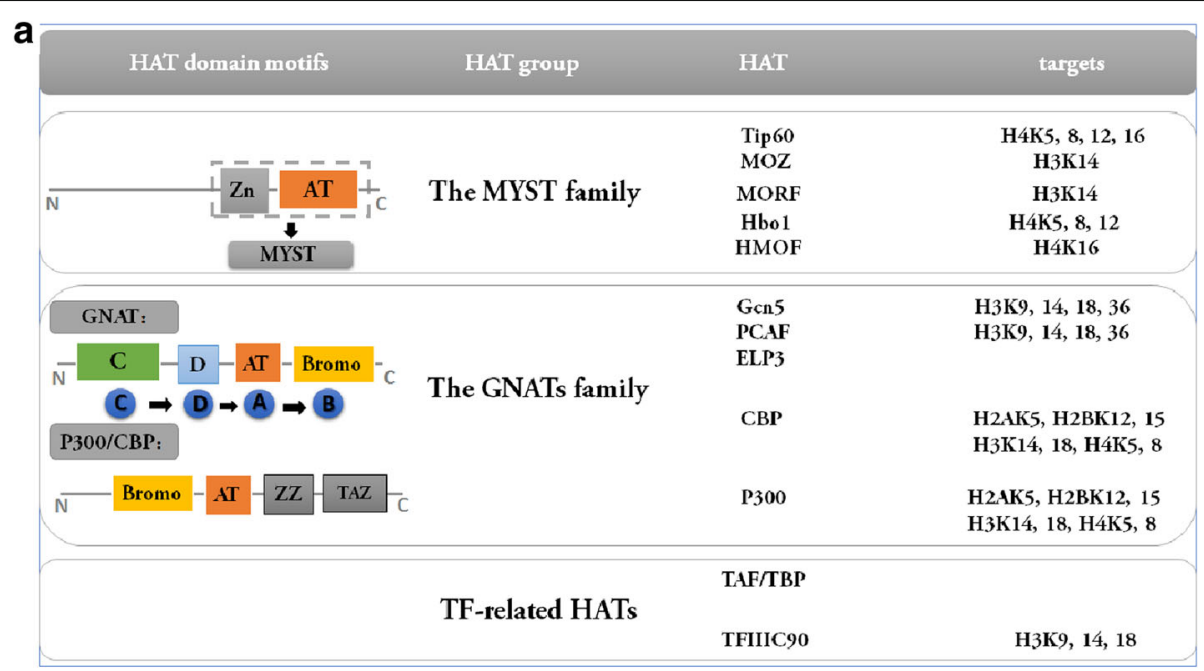

b

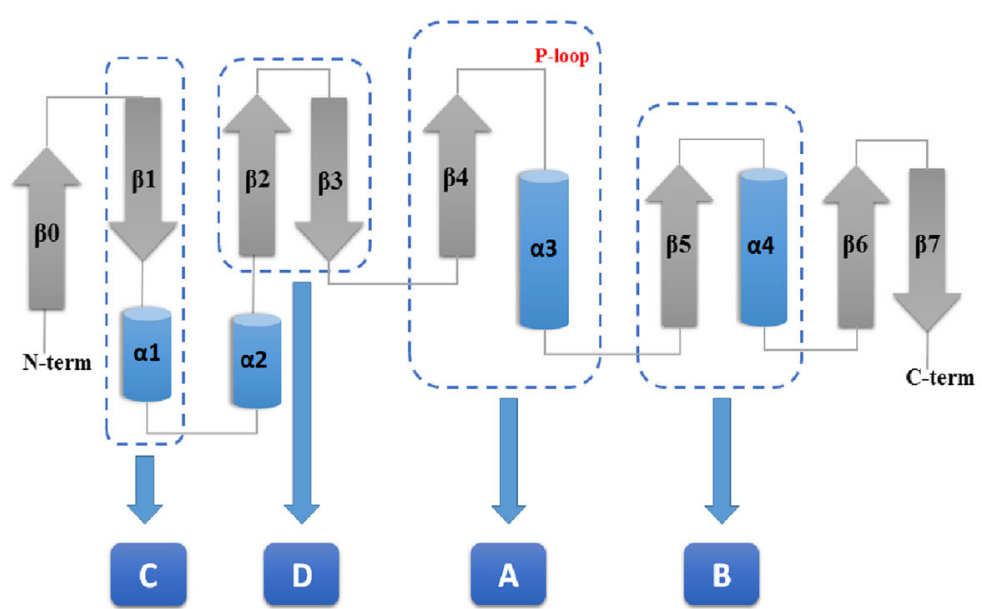

Fig. 2 a Type A HAT families. AT: acetyltransferase domain; Zn: Zic finger domain; Bromo: bromodomain. GNAT domain includes three key motifs and these motifs in structure is in this order: D-A-B. Some of GNAT family members contain another conserved motif $C$ that is located at the N-terminus of these proteins. $\mathbf{b}$ Topological diagram of the core GNAT fold. The highly conserved GNAT domain composed of 6-7 anti-parallel $\beta$-strands and 4 $a$-helices in the topology $\beta 1-\alpha 1-\alpha 2-\beta 2-\beta 3-\beta 4-\alpha 3-\beta 5-\alpha 4-\beta 6-\beta 7$. Motifs A and B participate in acyl-CoA and acceptor substrate recognition and binding, and the feature of motif $A$ is the "P-loop" that connect helix $a 3$ and strand $\beta 4$. Motifs $C$ and D preserve the stability of proteins

located in the cytoplasm. It acetylates free (not nuclear) histones. Interestingly, Hat1 is also found in the nucleus [31]. Type-B HATs acetylate newly synthesized histone H3 and H4 (Type-B HATs are mainly responsible for newly synthesized H4K5 and H4K12). Newly synthesized histones $\mathrm{H} 3$ and $\mathrm{H} 4$ are rapidly acetylated and then the modifications of acetylation are removed after the assembly of the histones into nucleosomes in the mature process of chromatin [31,32].

\section{The role of HATs in ovarian cancer}

Human males lack hMOF (also known as MYST1, a member of the MYST family of HATs), the human ortholog of the Drosophila MOF protein [33]. MOF contains a chromodomain and acetyl-CoA binding motif. Biochemical purifications reveal hMOF forms two distinct multicomplexes in mammalian cells: MSL (Male Specific Lethal)-associated MOF and NSL (NonSpecific Lethal)-associated MOF [34]. MSL-associated MOF exhibits strong specificity for histone H4K16 [27, 35]. NSL-MOF exhibits relaxed substrate specificity [36], and acetylates histone $\mathrm{H} 4$ at $\mathrm{K} 5,8$, and 16 [27, 34, 37, 38]. Depletion of hMOF reduces histone H4K16 acetylation, gene instability, and cell cycle disorder. Although the specific mechanisms hMOF plays in tumor development and progression are unclear, several studies demonstrate that abnormal hMOF gene expression in various cancers, including breast, renal cell, colorectal, gastric, and nonsmall cell lung cancer [39-42]. Recent studies demonstrated that HCP5 (human leukocyte antigen (HLA) 
complex 5) is a target gene of hMOF, and marked down-regulation of hMOF and HCP5, and loss of H4K16 acetylation were observed in ovarian epithelial cancer tissues [38, 43]. Immune system, as we known, prevents or controls tumor by monitoring cell biological behavior and identifying and eliminating abnormal cells. The aberrant expression of immune molecules like HLA-class I and II has been found in ovarian cancer (The human leukocyte antigen (HLA) system or complex is a gene complex encoding the major histocompatibility complex (MHC) proteins in humans) [44]. Moreover, HCP5 is localized within the MHC class I region and plays a key role in immunity to retrovirus infection [45]. Therefore, hMOF may have a role in modulation of tumor antigenspecific immune responses in ovarian cancer through modulating the expression of its target gene HCP5. Decreased hMOF levels are associated with reduced overall patient survival [43]. As such, hMOF protein expression is an independent risk factor influencing malignant ovarian tumor prognosis [38, 43]. hMOF may therefore have value as both a novel epigenetic biomarker for the diagnosis of malignant ovarian tumor, as well as a target for EOC treatment.

\section{Histone deacetylases (HDACs)}

HDACs remove acetyl residues, restoring the positive charge of lysine. Consequently, HDACs are associated with condensed chromatin structures and transcriptional repression [23].

\section{Classification and biology of HDACs}

Heretofore, the family of HDACs includes 18 isoenzymes, sorted into four classes (I-IV) based upon homology to yeast HDACs and sequence similarity (Fig. 3) [46]. Classes I, II, and IV are zinc-dependent enzymes. Class III (also known as sirtuins/SIRTs) are NAD+ dependent enzymes. Class I HDACs include HDAC 1, 2, 3, and 8 (all nuclear proteins). Of these, HDAC3 shuttles between the cytoplasm and nucleus. Class II HDACs include HDAC 4, 5, 6, 7, 9, and 10. All Class II HDACs shuttle between the cytoplasm and the nucleus. Class II consists of two subfamilies: IIa (HDAC 4, 5, 7, and 9) and IIb (HDAC 6 and 10). Subfamily IIa possess a highly conserved 600residue long $\mathrm{N}$-terminal extension. The $\mathrm{N}$-terminal extension possesses sites that bind myocyte enhancer factor 2 (MEF2) and 14-3-3 proteins. HDAC11 is the sole member of Class IV HDACs and share properties with both Class I and II. Class III HDACs are mammalian homologs of the yeast silent information regulator (SIR2), and include seven members (SIRT1-7) with possessing distinctive targets. Class III HDACs act as deacetylases for histones and non-histones [47-49].

\section{The role of HDACs in ovarian cancer Classical HDACs}

Class I (HDAC 1, 2, and 3) Class I HDACs (1, 2, and 3) promote ovarian cancer progression. Class I HDACs are over-expressed in ovarian cancer tissues, and play a critical role in ovarian carcinogenesis [50]. Moreover, expression of class I HDACs increases gradually from benign, borderline, and malignant ovarian tumors. Class I HDAC expression levels are markedly different in various histological ovarian cancer subtypes. Class I HDAC expression is most positive in mucinous subtypes, followed by high-grade serous, clear cell, and endometrioid subtypes. Strongly proliferating tumor tissues exhibit increased Class I HDAC expression. In addition, increased Class I HDAC expression is an independent risk factor for poor malignant ovarian tumor prognosis $[50,51]$. The specific mechanisms underlying how Class I HDACs facilitate ovarian carcinogenesis and chemo-resistance remain incompletely understood. Recently, a study further demonstrates the downregulatiom of RGS2 in drug-resistant ovarian cancer cells partly because Class I HDACs suppress the promoter region of RGS2 [52]. RGS2 (Regulator of G-protein Signaling 2) is an inhibitor of G-protein coupled receptors (GPCRs) via accelerating the deactivation of heterotrimeric G-proteins. The level of RGS2 dropped sharply in ovarian epithelial cells resistant to chemotherapy compared with chemo-sensitive cells has been observed [53]. HDAC1 enhances cellular proliferation via of cyclin A promotion [54]. HDAC2 remodels chromatin in response to platinum-based chemical therapies in ovarian epithelial cancer cells [15]. HDAC3 facilitates cellular migration by suppressing E-cadherin expression [54].

Interactions between the immune system and tumor critically impact prognosis. Recently, it has been demonstrated that ovarian cancer generates an immunosuppressive microenvironment to evade immune system attack. Proteins OX-40 ligand (OX-40 L/TNFSF4/CD134L/CD252) and 4-1BB ligand (4-1BBL/TNFSF9/CD137L) regulate effector cytotoxic T-cell (CTL) activity while programmed death ligand-1 (PD-L1) exhibits immunosuppressive effects, allowing the tumor to escape immune destruction [55]. Drug-resistant ovarian cancer cells exhibit repression of OX-40 L and 4-1BBL (immune-stimulatory molecules), with concomitant augmented expression of immunosuppressive molecules PD-L1/CD274 [56]. Furthermore, HDAC1 and HDAC3 exhibit aberrant association with OX-40 L and 4-1BBL promoters in chemotherapy-resistant ovarian cancer cells, contributing to suppression of OX-40 L and 4-1BBL [56]. EOC is one of the first malignancies demonstrating correlation between tumorinfiltrating lymphocytes (TILs) and increased overall survival rate $[55,57,58]$. Moreover, two HDAC1/ 2-derived HLA ligands activate T-cells, prompting further 


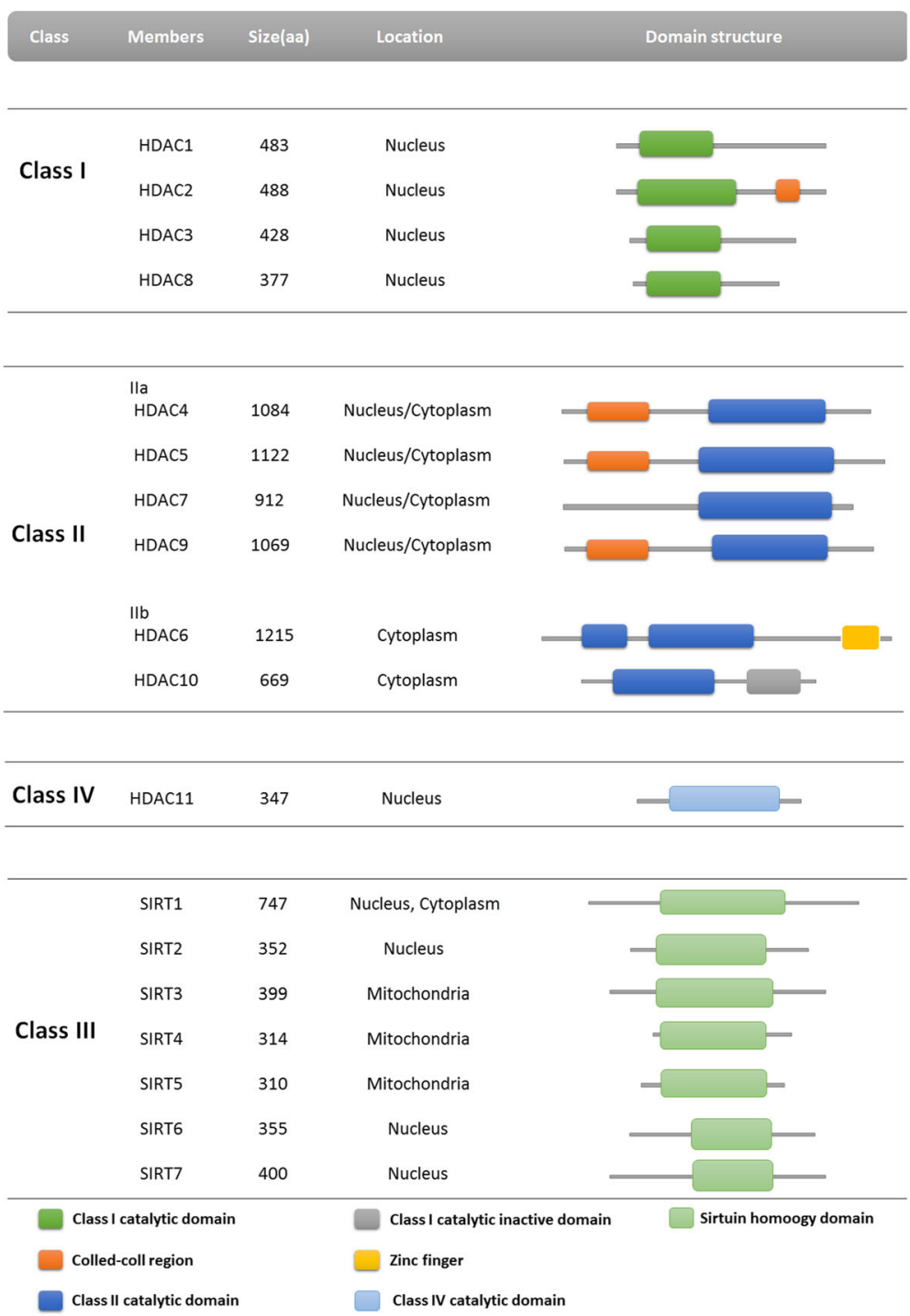

Fig. 3 HDAC families and their domain structure

elimination of HLA-matched cancer cells [59]. HDAC1 and HDAC7 maintain cancer stem cells (CSCs), both of which are over-expressed in ovarian cancer CSCs compared to non-stem tumor cells (NSTCs) [60]. Additionally, accumulation of HDAC4 (generated by nuclear fibrillar collagen matrices by PP1 $\alpha$ co-localization) suppresses p21, facilitating ovarian cancer cell proliferation, increasing invasive potential, and promoting migration [61].

\section{HDAC10}

The function of histone deacetylase 10 (HDAC10, a Class IIb member) in EOC is poorly understood. HDAC9 and HDAC10 are required for homologous recombination [62]. Recent evidence suggests HDAC10 inhibitors may augment platinum therapy efficacy in malignant ovarian tumors [63].

\section{SIRTs}

Yeast SIR2 (silent information regulator 2, member of the sirtuin family) was originally isolated during screening for cancer silencing factors [64]. SIR2 is a nicotinamide adenine dinucleotide (NAD+)-dependent enzyme, and is a histone deacetylase [64-66]. It is implicated with calorie restriction associated life span extension [67, 68]. Heretofore, 7 mammalian homologues (SIRT1-7) have been defined, with SIRT1 closest evolutionarily to yeast SIR2. Mammalian sirtuins target different sites, have diverse substrates, and influence various cellular functions.

\section{Sirtuin-1 (SIRT1)}

Of the 7 sirtuin family members, SIRT1 is among the most studied. SIRT1 has the highest homology to Yeast SIR2 [68]. SIRT1 protects against DNA damage and genomic 
instability, as well as cellular oxidative stress [69-71]. SIRT1 deacetylases both histones and non-histones (Fig. 4), and directly decreases the degree of acetylation of histone H1 K26, H3 K9, H3 K14, and H4 K16 [65, 72]. SIRT1 indirectly regulates histone methylation by interacting with methyltransferase SUV39H1 during heterochromatin formation [73]. The non-histone substrates of SIRT1 (transcriptional factors, DNA repair machinery elements, nuclear receptor genes, and signaling molecules) are critical in various biological processes, but are particularly important in carcinogenesis [74-77]. SIRT1 mediates deacetylation of p53, allowing cells with damaged DNA to bypass cell-cycle control, enabling mutation accumulation and, ultimately, carcinogenesis [78]. It may contribute to EOC development. SIRT1 is markedly increased in malignant ovarian tumors (especially, in serous carcinoma) compared to corresponding normal tissues, and up-regulated SIRT1 inactivates p53 by deacetylation [79]. SIRT1 overexpression is more common in early stage EOC [79]. EMT (epithelial-to-mesenchymal transition) occurs during early to invasive stage phenotypic tumor transition. SIRT1 regulates EMT in ovarian cancer cells, crucial in ALS-induced autophagy, antagonizing hypoxia-induced EMT [80]. SIRT1 is also implicated in LPA (lysophosphatidic acid)-induced EMT in ovarian cancer cells [59]. Ovarian cancer cell resistance to platinum-based drugs is largely attributed to increased SIRT1 expression [79, 81, 82]. The tumor suppressor gene BRCA1 regulates SIRT1 expression and NAD activity [83]. Crosstalk between SIRT1 and BRCA1 has been demonstrated but via unclear precise mechanisms. SIRT1 modulates cisplatin sensitivity in ovarian cancer via BRCA1-SIRT1-EGFR signaling [83, 84]. SIRT1 over-expression is pivotal in malignant ovarian tumor chemo-resistance, and may serve as a predictive indicator of poor clinical outcome [85].

\section{Sirtuin-3 (SIRT3)}

The Class III HDAC member SIRT3 functions as a malignancy inhibitor or facilitator dependent upon cancer type [86]. SIRT3 inhibits ovarian cancer cell migration via Twist down-regulation [87]. SIRT3 is requisite in the function of Bcl-2 suppressors in EOC, regulating both S1-mediated glucose metabolic and apoptotic effects [88].

\section{Sirtuin-6 (SIRT6)}

SIRT6 has been implicated in the development of colon adenocarcinoma, pancreatic, breast, and liver cancer [89-91]. As a tumor suppressor, SIRT6 is downregulated in ovarian cancer. SIRT6 inhibits ovarian cancer cell proliferation via Notch3 downregulation, and correlates with ovarian carcinoma prognosis [92].

\section{Histone methylation}

Histone methylation mainly occurs upon lysine or arginine residues. Methylation is required for various biological processes, ranging from post-transcriptional regulation to faithful chromosomal transmission during mitosis [93-95].

Unlike acetylation, however, histone methylation cannot alter histone protein charge [96]. Histone lysine methylation modulates either transcriptional activation (e.g. H3K4me1/ me2/m3, HK36me3, H3K79me1/me2/me3, H4R3me1, $\mathrm{H} 4 \mathrm{~K} 20 \mathrm{me} 1$ ) or gene silencing (e.g. H3K9me2/me3,

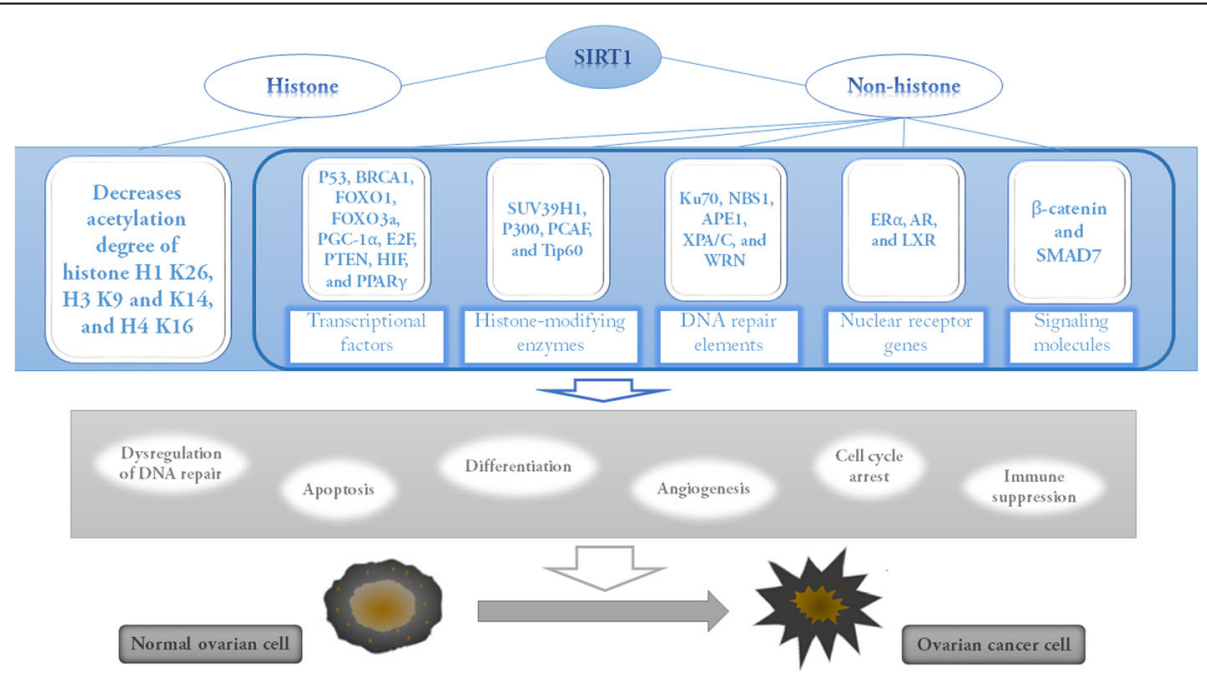

Fig. 4 A series of targets of SIRT1, and its multiple pathways that contribute to ovarian cancer. SIRT1 deacetylases both histones and non-histones. SIRT1 could directly decrease the degree of acetylation of histone $\mathrm{H} 1 \mathrm{~K} 26, \mathrm{H} 3 \mathrm{~K} 9, \mathrm{H} 3 \mathrm{~K} 14$, and $\mathrm{H} 4 \mathrm{~K} 16$, and also indirectly regulate the methylation and acetylation of histone by interacting with other histone-modifying enzymes such as SUV39H1, P300, PCAF, and Tip60. The non-histone substrates of SIRT1 (transcriptional factors, DNA repair machinery elements, nuclear receptor genes, and signaling molecules) are critical in the initiation and progression of ovarian cancer 
H3K27me3) depending upon 1) the particular residue methylated, 2) the degree of methylation, and 3) the site of the methylated histone within a specific gene locus. Moreover, histone methylation has stronger location-specificity than histone acetylation that generally links with transcriptional activation [97-99]. Histone modification leads to different biological consequences due to recruitment of diverse effector proteins $[98,100]$. The steady state of histone methylation is maintained by a balance between histone methyltransferases (HMTs) and histone demethylases (HDMTs). HMTs add methyl groups to the side chains of lysine and arginine. HDMTs catalyze methyl group removal. Therefore, imbalance between HMTs and HDMTs leads to aberrant gene expression, and carcinogenesis may ensue, including ovarian cancer [101-104].

\section{Histone methyltransferases (HMTs)}

HMTs are a large family of protein methyltransferases, adding methyl groups to lysine (HKMTs) or arginine (PRMTs). Both utilize SAM (S-Adenosyl-l-Methionine) as a methyl group donor. Lysine can be mono-, di-, or tri-methylated. Arginine residues of the core or tails of histones can be mono- or di- (asymmetric or symmetric) methylated [105].

\section{Classification and biology of HMTs Lysine methyltransferases (HKMTs)}

HKMTs are very sensitive and specific to the histone lysine residue they target, as well as the degree of methylation they can perform. Most lysine methyltransferases possess an evolutionarily conserved SET domain, referring to a multiprotein complex first identified in the Drosophila polycomb group proteins, namely suppressor of variegation 3-9 (Su(VAR)3-9), enhancer of zeste $(\mathrm{E}(\mathrm{z}))$, and trithorax (TRX) (Fig. 5) [106]. Lysine methyltransferases usually function within this multiprotein complex. The SET methyltransferase is responsible for the catalytic domain, while the others complex components account for selectivity and activity [107]. Centromeric heterochromatin is characterized by tri-methylated H3K9. Methylated H3K9 within the centromeric heterochromatin is requisite for recognition and binding of HP1 (heterochromatin protein 1). Suv39 loss directly induces down-regulation of H3К9 tri-methylation, influencing mitosis and meiosis [108]. Some SET demethylases are classified into subfamilies by structural sequence features: SET1, SET2, SUV39, EZ, RIZ, SMYD, and SUV4-20 subfamilies. Other SET domain-containing methyltransferases have not been classified into a specific group [107]. Additionally, the DOT1 (disruptor of telomeric silencing)-like family specifically methylates $\mathrm{H} 3 \mathrm{~K} 79$ at the histone globular core, maintaining meiosis stability. It does not contain the SET domain [109].

\section{Arginine methyltransferases (PRMTs)}

The multiple arginine residues within histone tails are mono- and di-methylated, affecting nucleosome remodeling and gene expression. Methylarginines have three different forms: Mono-methylated arginine (MMA), symmetric di-methylated arginine (SDMA), and asymmetric di-methylated arginine (ADMA) [110, 111]. There are nine known PRMTs in mammals, which are grouped into three classes: type-I, type-II, and type III enzymes. The type-I enzymes catalyze mono- and asymmetric di-methylation of arginine residues, and they include PRMT1, 2, 3, 4 (also known as CARM1), 6 , and 8 . The type-II enzymes catalyze mono- and symmetric di-methylation of arginine residues (PRMT5 and PRMT9 fall into this category). The type-III enzymes exclusively catalyze mono-methylation of arginine residues and only includes PRMT7 [111-113]. All of these enzymes catalyze the transfer of the methyl group to the guanidine nitrogen atom of arginine residues in a variety of histone, non-histone proteins, and various substrates. The most relevant enzymes in histone arginine methylation are PRMT1, 4, 5 and 6.

\section{The role of HMTs in ovarian cancer EZH2}

Enhancer of zeste homologue 2 (EZH2), a member of SET1 family, is an integral subunit of the polycomb repressive complex 2 (PRC2) and possesses histone methyltransferase activity on lysine- 9 and -27 of histone 3 or lysine-26 of histone 1 (Fig. 6). EZH2 is primarily responsible for $\mathrm{H} 3 \mathrm{~K} 27$ methylation, and the tri-methylated H3K27 (H3K27me3) is correlated with the gene silencing $[114,115]$. Additionally, the polycomb group protein EZH2 can also serve as a platform to recruit DNA methyltransferases and further directly control the methylation states of DNA [116]. The mammalian PRC2 complex mainly contains four core components: EZH2 (catalytic core component of PRC2), EED (Embryonic Ectoderm Development), SUZ12 (Zinc finger protein suppressor of Zeste 12), and RbAp46/48 [117, 118]. Different forms of the EZH2 complex exist in cells, which are distinguished by the different $\mathrm{N}$-terminal lengths of EED contained [118]. EZH2 is known to silence gene expression via trimethylation of histone $\mathrm{H} 3$ on lysine 27 (H3K27me3) [119]. However, recent evidence implicates a PRC2-independent role of transcriptional activation for EZH2. In a castration-resistant prostate cancer model, EZH2 acted as a co-activator for critical transcription factors including the androgen receptor (AR) that was independent of its transcriptional repressor function [120]. Moreover, EZH2 physically bridged the estrogen receptor (ER) and components of Wnt signaling to induce the gene expression in breast cancer cells [121]. EZH2 also activated NF-kB targets of NOTCH1 in breast cancer cells [122]. 


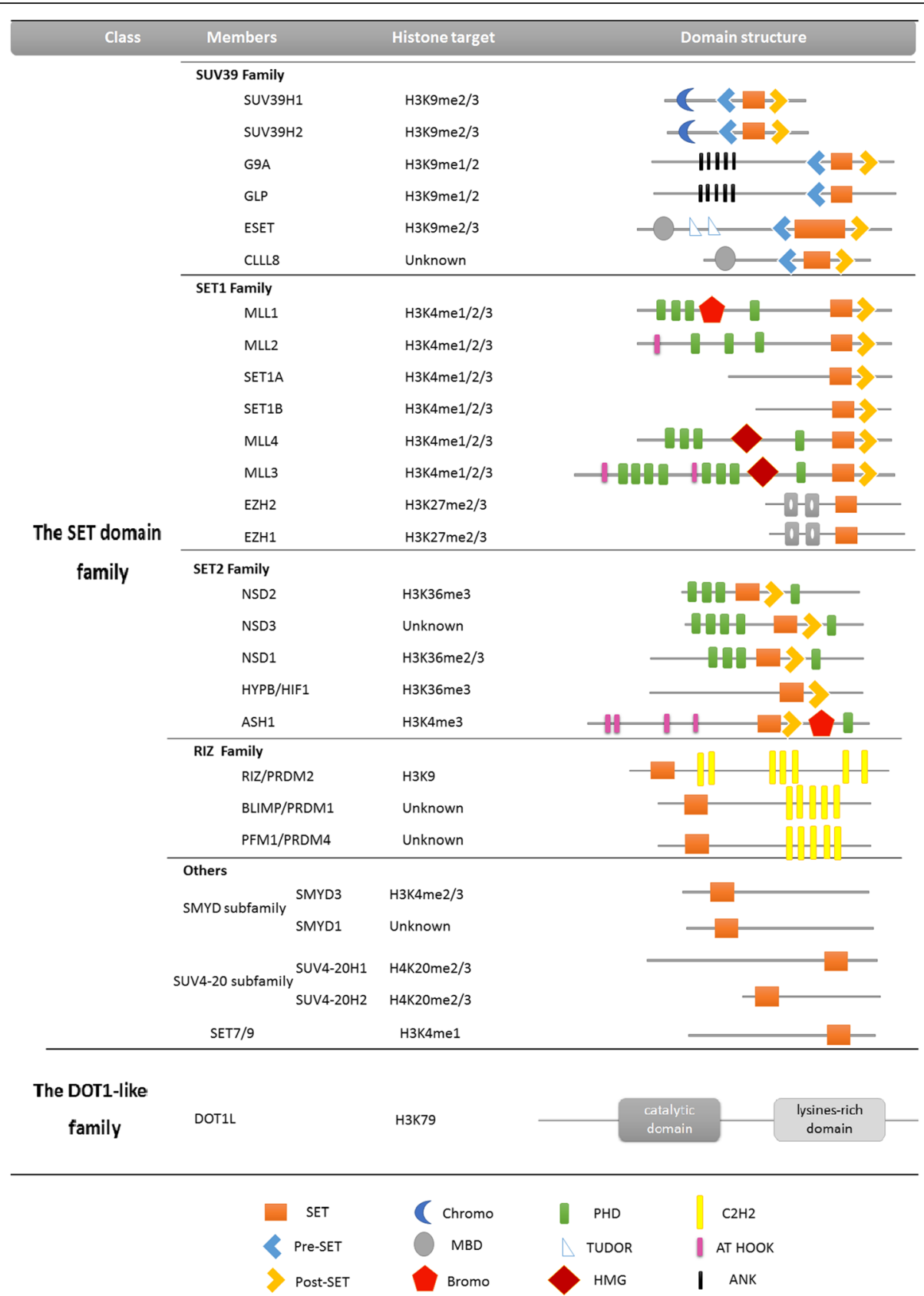

Fig. 5 Histone lysine methyltransferases(HKMTs): classfication, histone targets, primary domain architecture. HKMTs are classified in two types: the SET domain-containing proteins and the DOT1-like proteins. The SET domain-containing proteins can be subdivided into four families by structural sequence features: SUV39, SET1, SET2 and RIZ. Except for these family listed above, there are other SET domain -containing methyltransferases that have not been classfied into a specific group, for instance, SET8, SET7/9, SMYD subfamily and SUV4-20 subfamily

The expression of EZH2 is upregulated in many carcinomas, with the high level of EZH2 correlated with poor outcome of human tumors. EZH2 is involved in tumor initiation, development, progression, metastasis and chemoresistance through gene silencing and chromatin remodeling [123]. EZH2, as an oncogene, mainly functions to inhibit the expression of tumor suppressor genes through upregulating their methylation level. There is mounting evidence that up-regulation of EZH2 occurs in ovarian carcinoma, and is positively correlated with worsening histological grade and advanced stage [124]. EZH2 is thought to be an independent forecaster of poor overall survival for women with ovarian carcinoma [125-127]. Breast cancer 1 (BRCA1) gene is a well-recognized tumor suppressor gene, and the loss of BRCA1 is closely associated with ovarian carcinoma [128]. Recently, a study 


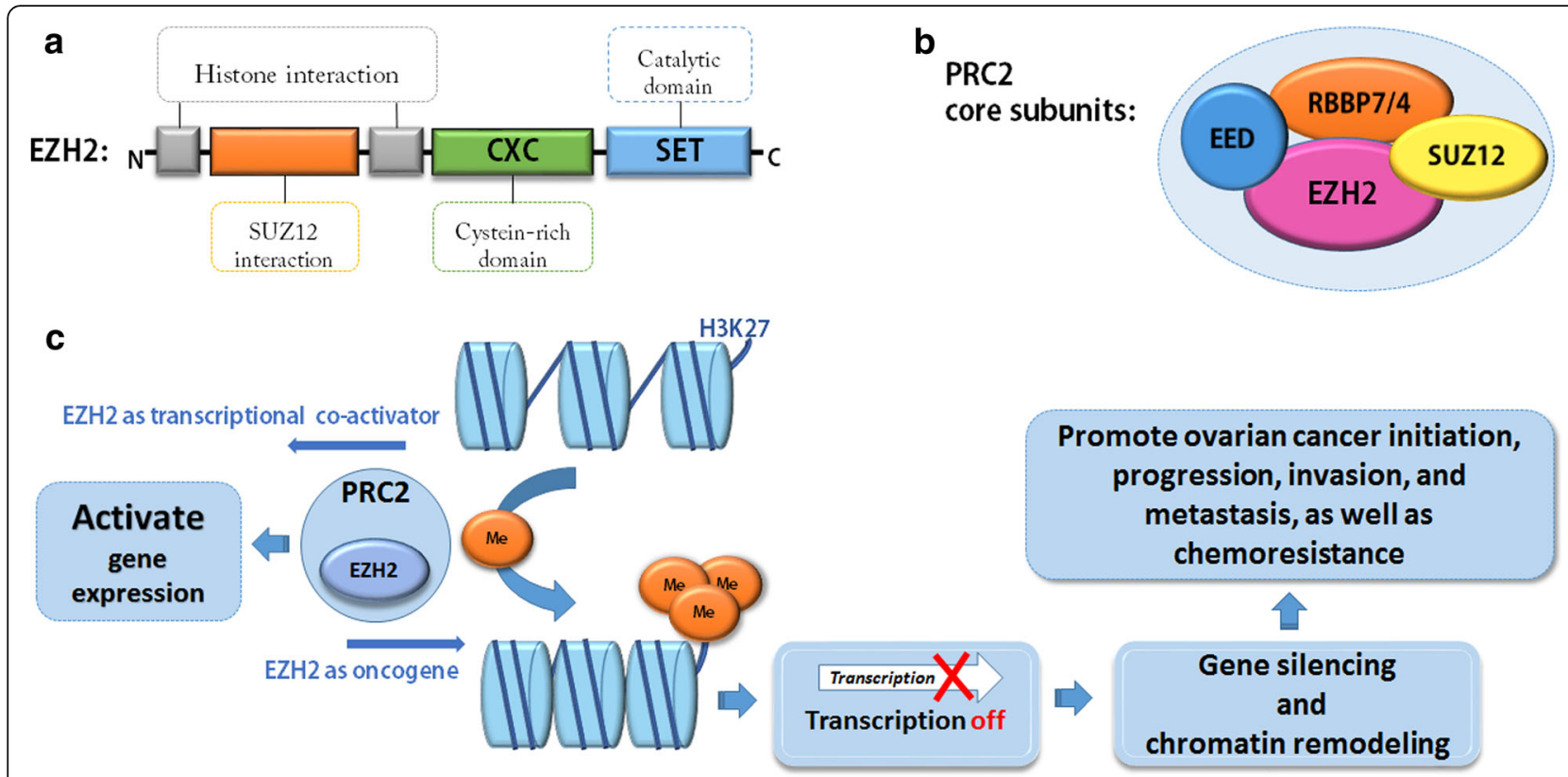

Fig. 6 The structure and function of EZH2. a. The schematic view of EZH2 principal domain; $\mathbf{b}$. Four core subunits of PRC2; $\mathbf{c}$. The schematic illustration of $\mathrm{EZH} 2$ function in ovarian cancer

has revealed that knockdown of EZH2 can rescue BRCA1 protein expression and facilitate its nuclear translocation. EZH2, therefore, may participates in biological behavior of EOC via modulating the expression of BRCA1 [127]. Moreover, the correlation between EZH2 and transforming growth factor-beta1 (TGF- $\beta 1$ ) has also been observed in ovarian carcinoma tissues. EZH2 promotes the ability for invasion and metastasis of ovarian carcinoma cells by regulating TGF- $\beta 1$ [129]. In detail, Rao et al. demonstrated that in ovarian carcinoma cell lines, EZH2 knockdown was found to reduce TGF- $\beta 1$ expression and increase E-cadherin expression either in the transcript or in the protein levels. Furthermore, a significant positive correlation between overexpression of EZH2 and TGFbeta1 in ovarian carcinoma tissues was observed, suggesting a potential important role of EZH2 in the control of cell migration and/or invasion via the regulation of TGF- $\beta 1$ expression.

Moreover, numerous studies support that EZH2 is critical to maintain a stem cell state [125]. The high expression of EZH2 has been implicated in maintenance of the cisplatin-resistant subpopulation of cells in ovarian carcinoma and contributes to acquired-tolerance for platinum-based chemotherapy [126]. Malignant ovarian tumor epigenetics could also be regulated by tumor microenvironment. Recent work has indicated that cancer-associated fibroblasts (CAFs) have an ability to enhance the growth and invasion of ovarian cancer cells, and this ability is partly due to increasing EZH2 expression [130].

\section{DOT1L}

Disruptor of telomeric silencing-1-like (DOT1L), a human homolog of yeast DOT1, is a unique histone methyltransferase that lacks the SET domain and is only responsible for methylating lysine-79 of histone $\mathrm{H} 3$ (H3K79) in the core domain [131]. According to recent findings, DOT1Lmediated H3K79 methylation serves as a key regulator in a number of physiological and pathological processes ranging from gene expression to DNA damage response and cell cycle regulation [132]. Zhang et al. first demonstrated that patients with ovarian carcinoma exhibiting high-level of DOT1L have poorer overall survival and progression-free survival as compared to those with low expression of DOT1L. This observation also suggested that DOT1L can directly regulate the transcription of G1 phase arrest genes CDK6 and CCND3 through H3K79 dimethylation to promote cell cycle progression [133]. The expression of DOT1L can be regarded as an independent predictive factor and a potential area for therapeutic intervention in ovarian cancer.

\section{PRMT1}

Protein arginine methyltransferase 1 (PRMT1), is an important arginine methyltransferase. It can serve as a transcriptional promotor or inhibitor by modifying a series of various substrates. PRMT1 is linked with many biological processes, including carcinogenesis [134, 135]. PRMT1 is a predominant asymmetric arginine methyltransferase in humans. Asymmetric di-methylation of histone $\mathrm{H} 4$ at arginine 3 (H4R3me2as) is mediated by 
PRMT1 and promotes transcriptional activation [136]. Increasing evidence has connected PRMT1 to the development and progression of cancer. Abnormal expression of PRMT1 has been seen with breast and prostate cancer $[137,138]$, and may have a role in the progression of ovarian carcinoma. Akter et al. suggest that PRMT1 is critical for the development of ovarian carcinoma. Knock-down of PRMT1 suppresses proliferation, migration, invasion, as well as colony formation of ovarian cancer cells. It has been shown that FAM98A, a new substrate of PRMT1, is expressed in ovarian cancer cell lines and is correlated with migration and invasion of ovarian cancer cells [110].

\section{PRMT5}

Arginine methyltransferase 5 (PRMT5), the first identified type II arginine methyltransferase [139], is the primary enzyme responsible for mono- and symmetric di-methylation of arginine. PRMT5 localizes to both the nucleus and the cytoplasm and it methylates multiple histone and non-histone proteins [111]. There is growing evidence that PRMT5 is involved in a wide variety of biological processes including cellular differentiation [140], proliferation [141], and apoptosis [142]. PRMT5 can directly methylate H4R3 and H3R8 to silence the tumor suppressor gene ST7 (suppression of tumorigenicity 7) and NM23 (nonmetastatic 23) [111, 143]. Additionally, it also can alter cell biological behaviors by methylating many other substrates, such as P53 [141], E2F1 [142], cyclin E1 [144] and E-cadherin [145]. Evidence has emerged that PRMT5 acts as an oncogene in ovarian cancer. The high level of PRMT5 is expressed in EOC and associated with poor outcome. Furthermore, the finding addresses that PRMT5 could substantially promote growth and proliferation of ovarian carcinoma cells depending on E2F-1 [146]. E2F-1 is a complex family of transcription factors and participates in the regulation of cell proliferation and cell cycle progression [147]. The down-regulation of PRMT5 may be a potential therapeutic target in malignant ovarian tumors. However, the precise role of PRMTs in ovarian cancer has not been elucidated. More studies are needed to explore the work of PRMTs in ovarian cancer.

\section{Histone demethylases (HDMTs)}

It had been thought that the methylation of histone was stable and irreversible, until 2004, when Shi et al. discovered lysine-specific demethylase 1A (LSD1; also known as KDM1A). LSD1 specifically removes methylation from mono- or di-methylated lysine 4 at histone H3 (H3K4me1 and H3K4me2) through its amine oxidase domain [148]. This revelation completely changed the concept of histone methylation.

\section{Classification and biology of HDMTs Lysine demethylases}

Histone lysine demethylases (KDMs) are classified into two categories: the flavin-dependent amine oxidase family and the jumonjic (JMJC) domain-containing family. Although these two families work on the lysine through different catalytic mechanisms, they have similar effects $[99,148]$.

All members of the amine oxidase-related family belong to the superfamily of the flavin adenine dinucleotide (FAD)-dependent enzymes that form an imine intermediate that is subsequently hydrolyzed to generate unmodified lysine and formaldehyde [149]. During the entire process, the cofactor FAD oxidizes the methyl-lysine and then the reduced FAD is re-oxidized by oxygen. Because the formation of the obligatory imine intermediate in this reaction requires a lone pair of electrons on the methy-lysine $\varepsilon$-nitrogen atom, LSD1 only removes mono-/di-methylation, not tri-methylation [148, 149]. While proteins in this superfamily have a JmjC domain, including six clusters (KDM2 to KDM7), they are a kind of enzymes apparently different from LSD-family, which can utilize $\mathrm{Fe}^{2+}$ and $\alpha$-ketoglutarate $(\alpha-K G)$ as cofactors to remove all 3 lysine methylation states (tri-, di- and mono-methylation) at H3K4, H3K9, H3K27, and H3K36, as well as H1K26 [149]. The JmjC lysine demethylases catalyze protein hydroxylation at the carbon of the $\mathrm{N \varepsilon}$ methyl group to produce an unstable hemiaminal intermediate, and $\mathrm{N} \varepsilon$-methyllysine demethylation by the hydroxylation [150].

\section{Arginine demethylases}

The human peptidylararginine deiminases 4 (PAD4/PADI4) is capable of transforming mono-methylated histone arginine to citrulline (Cit). However, as methylated arginine and non-methylated arginine can both be demethylated by PAD4/PADI4 and this demethylation reaction produces Cit, rather than arginine, PAD4/PADI4, to be exact, is not a "strict" histone demethylase [151]. In 2007, Chang et al. reported that Jumonji domain-containing 6 protein (JMJD6) is the only known member of the JmjC family that has the arginine demethylase activity and can demethylate histone $\mathrm{H} 3$ at arginine 2 (H3R2) and histone H4 at arginine 3 (H4R3) [152]. JMJD6 can catalyze two types of reactions: hydroxylation and demethylation. However, the latter catalytic mechanism is controversial [153]. Thus, the existence of a "true" histone arginine demethylase remains unclear.

\section{The role of HDMTs in ovarian cancer KDM1 subfamily}

Lysine-specific demethylase 1 (LSD1/KDM1A), the first H3K4 lysine-specific demethylase to be recognized [148], is a flavin-containing amine oxidase. It is a highly conserved protein that specifically catalyzes demethylation 
reactions on mono- and di-methylated histone $\mathrm{H} 3 \mathrm{~K} 4$ or H3K9. The structure of LSD1 bears three domains. It contains a C-terminal amine oxidase-like domain (AOL), a SWIRM domain located at the N-terminal, and a Tower domain that is inserted into the AOL domain and directly engages the SANT2 domain of CoREST (also known as RCOR1) [154]. The substrate specificity of LSD1 mainly lies on the type of partner. For example, LSD1, as a suppressor, can inactivate tumor suppressor genes via the activity of H3K4me2 demethylase. However, LSD1 can also promote transcription if it interacts with nuclear hormone receptors such as the androgen or estrogen receptors. Its enzymatic specificity switches to H3K9me2 $[155,156]$. LSD1 is not restricted to histone and it is also able to demethylate other nonhistones, such as p53 [157, 158].

Aberrant overexpression of LSD1 has been strongly correlated with poor prognosis in various kinds of human tumor types, such as hepatocellular, colon, breast, prostate, and non-small cell lung cancers [159-163]. Extensive studies have also demonstrated that LSD1 plays a crucial role in the early stages of carcinoma formation through chromatin remodeling [164, 165]. LSD1 can suppress p53-mediated apoptosis via demethylation of lysine-370 in p53 [158]. Previous reports have revealed that the expression of LSD1 is abundantly expressed in ovarian carcinoma tissues [166-169]. Moreover, one study observed that the level of LSD1 is improved from benign and borderline to malignant tumor in a stepwise manner, both in subtypes of serous and mucinous, and higher expression of LSD1 is linked strongly with FIGO stage and lymphatic metastasis in both ovarian serous cystadenocarcinoma and mucinous cystadenocarcinoma. Patients with a low level of LSD1 live longer than women with a high level of LSD1 expression [167]. A recent work shows that overexpression of LSD1 promotes ovarian carcinoma cell proliferation, migration, and invasion by regulating EMT. Knockdown of LSD1 impairs the ability of migration and invasion in ovarian cancer. Mechanistic analyses suggested that overexpression of LSD1 induces EMT and downregulates the transcription of E-cadherin which plays vital roles in regulating adhesion of cell-cell and maintenance of tissue architecture, with a concomitant upregulation of the mesenchymal markers (including $\mathrm{N}$-cadherin, Vimentin and MMP-2). Furthermore, upregulated LSD1 inhibits the transcription of E-cadherin by demethylating $\mathrm{H} 3 \mathrm{~K} 4 \mathrm{me} 2$ at the E-cadherin promoter. In addition, this study also observed that overexpressed LSD1 causes an increase in expression of transcription factor Snail that induces EMT through decreasing E-cadherin expression, and the loss of LSD1 leads to the downregulation of Snail [169]. Previous study showed that LSD1 is recruited through Snail to the region of E-cadherin promoter to inhibit the gene transcription of the E-cadherin consequently contributing to EMT-associated tumor cells invasion [170]. Sox2, a pluripotent stem cell (PSC) protein, is frequently expressed in many poor prognosis tumors and co-expressed with Oct4 and Lin 28 in ovarian cancer $[171,172]$. Sox 2 serves as a pivotal regulator to confer certain stem cell properties to ovarian cancer cells to allow them to grow, differentiate and survive. It has been reported that the expression of Sox 2 strongly depends on LSD1 expression [172, 173]. Downregulation of LSD1 represses the expression of Sox 2 and induces cell-cycle arrest through directly increasing the methylation states of H3K4 and H3K9 on region of Sox 2 and cell cycle genes. Strikingly, downregulation of LSD1 influences cellular differentiation through increase trimethylated H3K27. However, the upregulated level of trimethylated H3K27 is caused by the inhibition of Sox 2 after the loss of LSD1, rather than by LSD1 inactivation directly [173]. Thus, LSD1 is a critical factor in ovarian carcinoma cell growth and differentiation via a Sox2-mediated histone demethylation mechanism.

Many researchers have confirmed that overexpression of epidermal growth factor receptor (EGFR) signaling is closely correlated with poor outcome of ovarian cancer [174-176]. Recently, a report indicated that the level of LSD1 increases in parallel with increased the level of EGFR in ovarian cancer. More importantly, the high level of LSD1 is induced by EGF signaling. Furthermore, EGF increases LSD1 expression by activation of the phosphatidylinositol 3-kinase (PI3K)/AKT signaling pathway, with a decrease of H3K4me2 [169]. LSD1 is a critical player in EGF-mediated ovarian cancer mechanism. These findings suggest that LSD1 holds considerable promise as a novel biomarker for diagnosis and a target for treatment in ovarian cancer.

\section{KDM3 subfamily}

The KDM3 family histone demethylases, including KDM3A, KDM3B and JMJD1C, are H3K9me2/me1 demethylases with a preference for dimethylated residues. They could remove the methyl groups from $\mathrm{H} 3 \mathrm{~K} 9 \mathrm{me} 2$ to induce target gene expression activation [177]. They have been found to actively participate in the development and progression of a variety of cancers, including colorectal cancer [178], liver cancer [179], breast cancer [180] and Ewin sarcoma [181]. Recently, this superfamily has been found to regulate the malignant behaviors of ovarian cancers. Ramadoss et al. reported that KDM3A is a critical regulator of ovarian cancer stemness and cisplatin resistance [182]. KDM3A is crucial for the ovarian cancer cells to successfully progress through the critical stages of tumor progression such as cell proliferation, maintenance of CSCs and development of chemoresistance. To regulate these processes, KDM3A employs two distinct mechanisms; one by demethylating histone (H3K9me2) and the other 
by targeting a non-histone protein, p53. Mechanistically, while activating Sox 2 expression by erasing the repressive methylation (H3K9me2) mark, KDM3A modulates p21 and Bcl-2 expression possibly through p53-K372me1 demethylation. Consistently, KDM3A depletion inhibited the growth of subcutaneously implanted cisplatin-resistant human ovarian cancer cells in athymic nude mice. Moreover, KDM3A is abundantly expressed and positively correlated with Sox 2 expression in human ovarian cancer tissues. Thus, this report has unraveled a novel mechanism by which KDM3A promotes ovarian CSCs, proliferation and chemoresistance, underscoring the significance of KDM3A as a novel therapeutic target for resistant ovarian cancer.

\section{KDM4 subfamily}

Members of the KDM4/JMJD2 subfamily contain JMJD2A to JMJD2F. The KDM4/JMJD2 family is classified into two groups, based upon N-terminal JMJN and JMJC domain structure. JMJD2A, B, C belong to one group since their $\mathrm{N}$-terminal JMJN and JMJC domain are followed by two PHD and two TUDOR domains [183]. The remaining members of the KDM4 subfamily (JMJD2E and JMJD2F) are sorted into a second group. JMJD2E and JMJD2F are currently regarded as pseudogenes because of a lack of intrinsic sequences in their structure [184]. Various studies have shown that KDM4 is upregulated in many tumors and is unequivocally needed for cancer cell proliferation [185]. Abnormal tumor cell growth, proliferation and blood vessels formation consume large amounts of energy and oxygen and further lead to severe hypoxic microenvironment. The hypoxic microenvironment in turn can contribute significantly to a number of human tumors [186], including ovarian carcinoma [187, 188]. The response to hypoxia in human tumors primarily are mediated by hypoxia-inducible factor (HIF) [186]. HIF is a heterodimer (including a $\alpha$ and a $\beta$ subunits) and participates in a variety of tumor cell biological processes via inducing invasion, metastasis, angiogenesis, stem cell maintenance and resistance to chemotherapy and radiation. Accordingly, the expression of HIF is linked tightly with poor prognosis in human tumors [186, 189]. Multiple Jumonji-domain histone demethylases (JMJC-KDMs) can be regulated by HIF [190]. HIF- $1 \alpha$ induces expression of several Jumonji-domain histone demethylases (JMJC-KDMs), including the KDM4 family [185]. The well-studied member of the KDM4 family is KDM4A/ JMJD2A/JHDM3A. In general, the KDM4 family is suppressed in hypoxic microenvironment [185]. KDM4B/ JMJD2B is thought to influence gene expression by demethylating di- and tri-methylated histone 3 at lysine 9 (H3K9me2/me3) and lysine 36 (H3K36me2/me3). Recently, Wilson et al. demonstrated that hypoxia- inducible histone demethylase KDM4B is upregulated in ovarian cancer, and the mechanism of KDM4B that regulates the expression of metastatic genes and pathways, and facilitates peritoneal seeding and growth of ovarian cancer cells through hypoxic signaling [185]. Moreover, the hypoxia-inducible KDM3A, which could demethylate H3K9me2/1 in hypoxic states, may promote the function of KDM4B in ovarian cancer [185]. Studies have shown that KDM4A is either a promotor or suppressor in gene post-transcription. KDM4A can compose complexes with either androgen or estrogen receptors and then activate these complexes' activity through the KDM4A catalytic domain $[191,192]$. It remains unclear whether the inhibition requires KDM4A enzymatic activity consistent with an oncogenic function of KDM4A. The overexpression of KDM4A in ovarian cancer has previously been established. It is stabilized by hypoxia, independent of HIF, to promote gene amplification, copy number heterogeneity gain and drug resistance in ovarian cancer [193, 194]. Further researches investigating the mechanisms mediated through the KDM4 family in ovarian cancer is still warranted.

\section{KDM5 subfamily}

KDM5 subfamily (also known as JARID1) is composed of four multidomain members: JARID1A (KDM5A/RBP2), JARID1B (KDM5B/PLU1), JARID1C (KDM5C/SMCX), and JARID1D (KDM5D/SMCY). This family (with the exception of JMJC and JMJN domains), are recognized by the existence of ARID DNA binding [195], C5HC2 zinc finger motif, and several histone-interacting PHD domains [196]. All KDM5 members are capable of removing methyl groups from di- and tri-methylated histone 3 at lysine 4 (H3K4me2/me3). In actively transcribed genes, this occurs at the starting region of transcription. Evidence suggests that the KDM5 subfamily acts as a driver in carcinogenesis [197]. KDM5A and KDM5B induces the growth of cancer cells, reduces the expression of tumor suppressor genes, facilitates the acquired tolerance of cancer-fighting drugs, and maintains tumor-initiating cells [198]. Recent data has shown that KDM5B exhibits frequent gain of function for alterations in ovarian cancer and the high level of KDM5B is closely associated with poor outcome and acquired drug resistance in malignant ovarian tumor [199]. KDM5B may act as a key biomarker to predict prognosis and acquired chemoresistance for patients with ovarian carcinoma. More interestingly, high KDM5A/B expression characterizes a small subpopulation of slowly cycling, tumor-initiating cells that are intrinsically resistant to a wide variety of cancer therapeutics, including both cytotoxic (e.g. Cis-platinum) and targeted agents (tyrosine kinase inhibitors, Bortezomib, B-raf inhibitors) [200-202]. Inhibition of KDM5A/B may prove useful in combination with conventional therapies to combat drug tolerance of ovarian cancer patients. 
Although the previously described demethylases have been reported in ovarian cancer and implicated in tumorigenesis, the exact mechanism is not completely understood. It remains unclear whether the function of the remaining enzymes of demethylases are responsible for the onset and progression of ovarian carcinoma.

\section{Clinical applications}

\section{Histone deacetyltransferase inhibitors (HDACis)}

HDACis, as chromatin-modifying drugs, block HDACs and subsequently induces an increase in the acetylated level of histones. This stimulates the reactivation of silenced tumor suppressor genes and reverses the aberrant phenotype of malignant tumors. HDACis also induce differentiation of CSCs from their quiescent state. Other mechanisms of HDACis have also been identified, such as the generation of oxidative stress [203]. The inhibitors of histone deacetyltransferase represent a completely new insight into the therapy of malignant ovarian tumor and resistance to anti-cancer drugs. Several classes of HDACis have been identified, including organic hydroxamic acids, short-chain fatty acids, benzamides, cyclic tetrapeptides, and sulfonamide anilides [202]. Only three HDAC inhibitors have been approved by the FDA: vorinostat, romidepsin, and panobinostat. All three drugs have been successfully tested on ovarian cancer, either alone or in combination with other anti-cancer drugs such as cisplatin [204].

Many other HDACis are undergoing rapid development and have also been tested under preclinical and clinical investigation with potential to become anti-cancer drugs for ovarian cancer. For example, the HDAC inhibitor Trichostatin A (TSA), a drug that displays great inhibition for class I and II HDACs, can induce gene expression of P73 and facilitate Bax-dependent apoptosis in ovarian cancer cells with the acquired resistance of cisplatin [205]. Currently, TSA is still in the stage of preclinical stage for the treatment of ovarian cancer. Belinostat (Bel, PXD101) is a low molecular weight class I and II HDAC inhibitor of the hydroxamate class which alters acetylation levels of histone and non-histone proteins [206]. It has been investigated as a potent anti-tumor agent in a variety of cancers, including ovarian cancer. A Gynecologic Oncology Group (GOG) study was conducted to evaluate the impact of belinostat, in combination with carboplatin in women with platinum-resistant ovarian cancer. This study had 29 women enrolled and 27 were evaluable. The median number of cycles given was two (range 1-10). One patient had a complete response and one had a partial response, for an ORR of 7.4\% (95\% CI, .9-24.3\%). Twelve patients had stable disease while eight had increasing disease. Response could not be assessed in five (18.5\%). Grade 3 and 4 events occurring in more than $10 \%$ of treated patients were uncommon and limited to neutropenia (22.2\%), thrombocytopenia (14.8\%), and vomiting (11.1\%). The median progression-free survival (PFS) was 3.3 months and overall survival was 13.7 months. PFS of at least 6 months was noted in 29.6\% of patients. Due to the lack of drug activity, the study was closed after the first-stage [207]. Nevertheless, Dizon et al. further initiated a phase $1 \mathrm{~b} / 2$ study was performed, with an exploratory phase 2 expansion planned specifically for women with recurrent EOC to evaluate the clinical activity of belinostat, carboplatin, and paclitaxel (BelCaP) [208]. Thirty-five women were treated on the phase 2 expansion cohort. BelCap was given as follows: belinostat, $1000 \mathrm{mg} / \mathrm{m}^{2}$ daily for 5 days with carboplatin, AUC 5 ; and paclitaxel, $175 \mathrm{mg} / \mathrm{m}^{2}$ given on day 3 of a 21 -day cycle. The primary end point was overall response rate (ORR), using a Simon 2 stage design. The results showed that $54 \%$ had received more than two prior platinum-based combinations, 16 patients $(46 \%)$ had primary platinum-resistant disease, whereas 19 patients (54\%) recurred within 6 months of their most recent platinum treatment. The median number of cycles of BelCaP administered was 6 (range, 1-23). Three patients had a complete response, and 12 had a partial response, for an ORR of 43\% (95\% confidence interval, 26-61\%). When stratified by primary platinum status, the ORR was $44 \%$ among resistant patients and $63 \%$ among sensitive patients. The most common drug-related adverse events related to BelCaP were nausea (83\%), fatigue (74\%), vomiting (63\%), alopecia (57\%), and diarrhea (37\%). With a median follow-up of 4 months (range, 0-23.3 months), 6-month progression-free survival is $48 \%$ ( $95 \%$ confidence interval, 31-66\%). Median overall survival was not reached during study follow-up. The results showed that belinostat, carboplatin, and paclitaxel combined was reasonably well tolerated and demonstrated clinical benefit in heavily-pretreated patients with epithelial ovarian cancer. The addition of belinostat to this platinum-based regimen represents a novel approach to epithelial ovarian cancer therapy and warrants further exploration. Other information on the use of HDACis in ovarian cancer has been listed in Table 1. Although HDACis as a new class of anti-cancer drugs are quite frequently researched in the field of ovarian cancer, the underlying mechanisms remain unclear. Additionally, a huge issue concerning the development of HDACis in the therapy of human tumor (including ovarian cancer) is that most of them have severe side effects due to cytotoxicity to normal cells. Therefore, better selective inhibitors of HDAC should be explored for ovarian cancer treatment.

\section{The inhibitors of HMTs or HDMTs}

The balance between HMTs and HDMTs is required to keep the level stable for histone methylation. The imbalance between histone methylation and demethylation has been frequently found in ovarian carcinoma and is caused 
Table 1 Inhibitors of epigenetic modifications for the treatment of ovarian cancer

\begin{tabular}{|c|c|c|c|c|c|}
\hline \multicolumn{2}{|c|}{ Classification } & \multirow{2}{*}{$\begin{array}{l}\text { Drug } \\
\text { Trichostatin A(TSA) }\end{array}$} & \multirow{2}{*}{$\begin{array}{l}\text { Target } \\
\text { Class I and II HDAC families }\end{array}$} & \multirow{2}{*}{$\begin{array}{l}\text { Phase } \\
\text { Preclinical }\end{array}$} & \multirow{2}{*}{$\begin{array}{l}\text { Reference } \\
{[214]}\end{array}$} \\
\hline $\mathrm{HDACi}$ & Hydroxamic acid & & & & \\
\hline & & Panobinostat(LBH589) & Class I and II HDAC families & Phase I & {$[215,216]$} \\
\hline & & Belinostat(PXD101) & Class I and II HDAC families & Phase II & {$[207,208]$} \\
\hline & Short-chain fatty acid & Valproic acid(VPA) & Class I and Ila HDAC families & Phase I and Phase III & NCT00529022; NCT00533299 \\
\hline & Cyclic peptide & Romidepsin(FK288) & Class I HDAC family & Phase II & $\begin{array}{l}\text { NCT00091195(Terminated); } \\
\text { NCT00085527(Withdrawn) }\end{array}$ \\
\hline & Benzamide & Mocetinostat(MGCD0103) & Class I HDAC family & Preclinical & {$[217]$} \\
\hline HKMTi & $\begin{array}{l}\text { S-adenosylhomocysteine } \\
\text { hydrolase inhibitor }\end{array}$ & $\begin{array}{l}\text { 3-Deazaneplanocin } \\
\text { A(DZNEP) }\end{array}$ & Polycomb group proteins & Preclinical & [209] \\
\hline HDMTi & Polyamine analog & Polyamine analog & LSD1 & Preclinical & {$[218]$} \\
\hline
\end{tabular}

by mutations and aberrant gene expression. A number of inhibitors have been studied to target HMTs and HDMTs and are promising for ovarian cancer therapy. Development of histone methylation modulators is still in its preliminary stages. Currently, several inhibitors of HKMTs have been developed. 3-Deazaneplanocin A (DZNEP), the first indirect inhibitor of $\mathrm{EZH} 2$, was reported to be a promising cancer-fighting agent for malignant ovarian tumor, with potential to reduce proliferation, induce apoptosis, and inhibit metastasis [209]. More interestingly, Bitler et al. demonstrated that EZH2 inhibitor, GSK126, acts in a synthetic lethal manner in ARID1A-mutated ovarian cancer cells and that ARID1A mutational status correlated with response to the EZH2 inhibitor [210]. PIK3IP1 was identified as a direct target of ARID1A and EZH2 that is upregulated by EZH2 inhibition and contributed to the observed synthetic lethality by inhibiting PI3K-AKT signaling. Moreover, EZH2 inhibition caused regression of ARID1A-mutated ovarian tumors in vivo. Thus pharmacological inhibition of EZH2 represents a novel treatment strategy for ovarian cancers involving ARID1A mutations. In addition, a number of inhibitors of LSD1 also have been applied in ovarian cancer. However, most of them are non-selective to inhibit the activity of LSD1 [211]. Currently, some selective and potent LSD1 inhibitors have emerged [212], such as S2101. S2101 could suppress ovarian cancer cells via inducing autophagy and apoptosis. Additionally, the inhibition of AKT/mTOR signaling pathway also contributes to the anti-cancer effect of S2101 in ovarian cancer cells [213]. The use of nonselective compounds is restricted due to the undesirable side effects. Thus the synthesis of more selective derivatives needs to be discovered.

\section{Novel directions for epigenetic histone modification in the clinical management of ovarian cancer}

As epigenetic inhibitors are an emerging therapy in ovarian cancer, and with development of more selective HDACi and perhaps targeting histotypes most likely to respond, this approach may find a way into clinical care. Moreover, with development of resistance to traditional chemotherapeutic regimens and the emerging immunotherapy, a combinatory treatment with epigenetic inhibitors might open a new avenue to fight against this deadly disease. Modern computational biology approaches will also guide the precision medicine therapy for the selection of epigenetic inhibitors for the treatment of specific histotypes of ovarian cancer. Studies of histone modification proteins are more nascent, yet clinical trials in inhibitors of these proteins are underway. Much more is needed to be done to fully realize the potential that epigenetics holds for ovarian cancer clinical care.

\section{Conclusion and perspective}

Malignant tumor formation is associated with gene alteration and epigenetic change. Although genetic alterations cannot be reversed, epigenetic changes are reversible and thus are easy to modulate. Epigenetics may serve as the basis of the development of diagnostic tools aiding in early detection of malignant ovarian tumor. Aberrant histone acetylation and methylation alter gene expression, with potential clinical consequences of malignancy. In recent years, the study of histone modification and the involved regulatory enzymes have accelerated the identification of potential diagnostic and prognostic biomarkers for ovarian cancer. Epigenetic therapy, especially the modulators of histone-modifying enzymes, has been under the spotlight in ovarian cancer research. However, the comparative low specificity of these epigenetic drugs might lead to undesirable side effects to human, hampering its widespread clinical application. Modern scientist are endeavoring to discover novel generations of epigenetic drugs based upon the biological effects of this histone-modifying enzymes with maximal therapeutic efficacy and minimal toxicities. Although there is still a long way to go, epigenetics-based biomarker profiling and therapeutic regimens may provide a powerful weapon to fight against ovarian cancer. 


\section{Abbreviations}

ADMA: Asymmetric di-methylated arginine; AR: Androgen receptor; BRCA1: Breast cancer 1; CAFs: Cancer-associated fibroblasts; CSCs: Cancer stem cells; CTL: Cytotoxic T-cell; DOT1: Disruptor of telomeric silencing-1; DOT1L: Disruptor of telomeric silencing-1-like; DZNEP: 3-Deazaneplanocin A; EED: Embryonic ectoderm development; EGFR: Epidermal growth factor receptor; EMT: Epithelial-to-mesenchymal transition; EOC: Epithelial ovarian cancer; ER: Estrogen receptor; EZH2: Enhancer of zeste homologue 2; GNAT: GCN5-related N-acetyltransferases; GOG: Gynecologic Oncology Group; GPCRs: G-protein coupled receptors; HATs: Histone acetyltransferases; HDACs: Histone deacetylases; HDMTs: Histone demethylases; HE4: Human epididymis protein 4; HGSC: High grade serous carcinoma; HIF: Hypoxiainducible factor; HLA: Human leukocyte antigen; HMTs: Histone methyltransferases; JMJD6: Jumonji domain-containing 6 protein; LPA: Lysophosphatidic acid; LSD1: Lysine-specific demethylase 1A; MEF2: Myocyte enhancer factor 2; MHC: Major histocompatibility complex; MMA: Mono-methylated arginine; NM23: Nonmetastatic 23; NSTCs: Non-stem tumor cells; ORR: Overall response rate; PD-L1: Programmed death ligand-1; PFS: Progression-free survival; PI3K: Phosphatidylinositol 3-kinase;

PRC2: Polycomb repressive complex 2; PRMTs: Arginine methyltransferases; RGS2: Regulator of G-protein signaling 2; ROCA: Risk of ovarian cancer algorithm; SAM: S-Adenosyl-I-Methionine; SDMA: Symmetric di-methylated arginine; SIR2: Silent information regulator 2; SUZ12: Zinc finger protein suppressor of Zeste 12; TGF-beta1: Transforming growth factor-beta1; TILs: Tumor-infiltrating lymphocytes; TRX: Trithorax; TSA: Trichostatin A

\section{Acknowledgements}

We thank Dr. Wayne Bond Lau and Dr. Bonnie Lau for careful proofreading and language polishing of our manuscript.

\section{Funding}

Supported by grants from National Natural Science Foundation of China (grant \# 81773119 and \#81402396), National Key Research and Development Program focused on Stem Cell and Translational Research (grant \# 2017YFA0106800), Sichuan Science-Technology Soft Sciences Project (grant \#2016ZR0086), Clinical Research Foundation of West China Second Hospital (grant \#KL004), Yi Yao Foundation (grant \#14H0563) and Direct Scientific Research Grants from West China Second Hospital, Sichuan University (grant \#KS021).

\section{Availability of data and materials}

Data sharing is not applicable to this article as no datasets were generated or analysed during the current study.

\section{Authors' contributions}

LIZ and STZ provided direction and guidance throughout the preparation of this manuscript. QLY, YQY, NXZ, KXT, WW, LX, ZNY, SH collected and prepared the related literature. QLY, LJZ, and STZ drafted the manuscript. $X W, T Y, X Z$, and YQW reviewed and made significant suggestions to the manuscript. WBL and BL made critical editing for the English language. All authors have read and approved the final manuscript. YQY, KXT and HJW made crucial revision work to the manuscript.

\section{Ethics approval and consent to participate} Not applicable.

\section{Consent for publication}

All authors have reviewed the manuscript and agree to publish it in its current form.

\section{Competing interests}

The authors declare that they have no competing interests.

\section{Publisher's Note}

Springer Nature remains neutral with regard to jurisdictional claims in published maps and institutional affiliations.

\section{Author details}

'Department of Obstetrics and Gynecology, Key Laboratory of Birth Defects and Related Diseases of Women and Children of MOE and State Key Laboratory of Biotherapy, West China Second University Hospital, Sichuan University and Collaborative Innovation Center, Chengdu 610041, People's
Republic of China. ${ }^{2}$ Nanchang University, Nanchang, People's Republic of China. ${ }^{3}$ Sichuan Normal University Affiliated Middle School, Chengdu, People's Republic of China. ${ }^{4}$ Department of Emergency Medicine, Thomas Jefferson University Hospital, Philadelphia, USA. ${ }^{5}$ Department of Surgery, Emergency Medicine, Kaiser Santa Clara Medical Center, Affiliate of Stanford University, Stanford, USA. ${ }^{6}$ Department of Biomedical Sciences, City University of Hong Kong, Kowloon Tong, Hong Kong, China. ${ }^{7}$ Department of Pathology, West China Second University Hospital, Sichuan University, Chengdu, People's Republic of China.

Received: 23 December 2017 Accepted: 11 July 2018 Published online: 31 July 2018

\section{References}

1. Ko SY, Naora H. Therapeutic strategies for targeting the ovarian tumor stroma. World J Clin Cases. 2014;2:194-200.

2. Pchejetski D, Alfraidi A, Sacco K, Alshaker H, Muhammad A, Monzon L. Histone deacetylases as new therapy targets for platinum-resistant epithelial ovarian cancer. J Cancer Res Clin Oncol. 2016;142:1659-71.

3. Jemal A, Siegel R, Xu J, Ward E. Cancer statistics, 2010. CA Cancer J Clin. 2010;60:277-300.

4. Visintin I, Feng Z, Longton G, Ward DC, Alvero AB, Lai Y, Tenthorey J, Leiser A, Flores-Saaib R, Yu H, et al. Diagnostic markers for early detection of ovarian cancer. Clin Cancer Res. 2008;14:1065-72.

5. Jordan S, Steer C, DeFazio A, Quinn M, Obermair A, Friedlander M, Francis J, O'Brien S, Goss G, Wyld D, et al. Patterns of chemotherapy treatment for women with invasive epithelial ovarian cancer--a population-based study. Gynecol Oncol. 2013;129:310-7.

6. Vogelstein B, Kinzler KW. Cancer genes and the pathways they control. Nat Med. 2004;10:789-99.

7. Asadollahi R, Hyde CA, Zhong XY. Epigenetics of ovarian cancer: from the lab to the clinic. Gynecol Oncol. 2010;118:81-7.

8. Esteller M. Epigenetics in cancer. N Engl J Med. 2008;358:1148-59.

9. Maradeo ME, Cairns P. Translational application of epigenetic alterations: ovarian cancer as a model. FEBS Lett. 2011;585:2112-20.

10. Kwon MJ, Shin YK. Epigenetic regulation of cancer-associated genes in ovarian cancer. Int J Mol Sci. 2011;12:983-1008.

11. Becker PB, Workman JL. Nucleosome remodeling and epigenetics. Cold Spring Harb Perspect Biol. 2013;5:a017905.

12. Jenuwein T, Allis CD. Translating the histone code. Science. 2001;293:1074-80.

13. Strahl BD, Allis CD. The language of covalent histone modifications. Nature. 2000;403:41-5.

14. Haberland M, Montgomery RL, Olson EN. The many roles of histone deacetylases in development and physiology: implications for disease and therapy. Nat Rev Genet. 2009;10:32-42.

15. Huang R, Langdon SP, Tse M, Mullen P, Um IH, Faratian D, Harrison DJ. The role of HDAC2 in chromatin remodelling and response to chemotherapy in ovarian cancer. Oncotarget. 2016;7:4695-711.

16. Kobayashi H, Yamada Y, Sado T, Sakata M, Yoshida S, Kawaguchi R, Kanayama S, Shigetomi H, Haruta S, Tsuji Y, et al. A randomized study of screening for ovarian cancer: a multicenter study in Japan. Int J Gynecol Cancer. 2008;18:414-20.

17. Matulonis UA, Sood AK, Fallowfield L, Howitt BE, Sehouli J, Karlan BY. Ovarian cancer. Nat Rev Dis Primers. 2016;2:16061.

18. Buys SS, Partridge E, Black A, Johnson CC, Lamerato L, Isaacs C, Reding DJ, Greenlee RT, Yokochi LA, Kessel B, et al. Effect of screening on ovarian cancer mortality: the prostate, lung, colorectal and ovarian (PLCO) Cancer screening randomized controlled trial. JAMA. 2011;305:2295-303.

19. Jacobs IJ, Menon U, Ryan A, Gentry-Maharaj A, Burnell M, Kalsi JK, Amso NN, Apostolidou S, Benjamin E, Cruickshank D, et al. Ovarian cancer screening and mortality in the UK collaborative trial of ovarian Cancer screening (UKCTOCS): a randomised controlled trial. Lancet. 2016;387:945-56.

20. Cao H, You D, Lan Z, Ye H, Hou M, Xi M. Prognostic value of serum and tissue HE4 expression in ovarian cancer: a systematic review with meta-analysis of 90 studies. Expert Rev Mol Diagn. 2018;18:371-83.

21. Wu L, Dai ZY, Qian YH, Shi Y, Liu FJ, Yang C. Diagnostic value of serum human epididymis protein 4 (HE4) in ovarian carcinoma: a systematic review and meta-analysis. Int J Gynecol Cancer. 2012;22:1106-12.

22. Maritschnegg $E$, Wang $Y$, Pecha $N$, Horvat $R$, Van Nieuwenhuysen $E$, Vergote I, Heitz F, Sehouli J, Kinde I, Diaz LA Jr, et al. Lavage of the uterine cavity for 
molecular detection of Mullerian duct carcinomas: a proof-of-concept study. J Clin Oncol. 2015:33:4293-300.

23. Shahbazian MD, Grunstein M. Functions of site-specific histone acetylation and deacetylation. Annu Rev Biochem. 2007;76:75-100.

24. Bannister AJ, Kouzarides T. Regulation of chromatin by histone modifications. Cell Res. 2011;21:381-95.

25. Avvakumov N, Cote J. The MYST family of histone acetyltransferases and their intimate links to cancer. Oncogene. 2007;26:5395-407.

26. Vetting MW, SdC LP, Yu M, Hegde SS, Magnet S, Roderick SL, Blanchard JS Structure and functions of the GNAT superfamily of acetyltransferases. Arch Biochem Biophys. 2005;433:212-26.

27. Srivastava P, Khandokar YB, Swarbrick CM, Roman N, Himiari Z, Sarker S, Raidal SR, Forwood JK. Structural characterization of a Gcn5-related Nacetyltransferase from Staphylococcus aureus. PLoS One. 2014;9:e102348

28. Marmorstein R. Structure of histone acetyltransferases. J Mol Biol. 2001;311: 433-44.

29. Hodawadekar SC, Marmorstein R. Chemistry of acetyl transfer by histone modifying enzymes: structure, mechanism and implications for effector design. Oncogene. 2007;26:5528-40.

30. Thompson PR, Wang D, Wang L, Fulco M, Pediconi N, Zhang D, An W, Ge $\mathrm{Q}$, Roeder RG, Wong J, et al. Regulation of the p300 HAT domain via a novel activation loop. Nat Struct Mol Biol. 2004;11:308-15.

31. Parthun MR. Hat1: the emerging cellular roles of a type B histone acetyltransferase. Oncogene. 2007;26:5319-28.

32. Haigney A, Ricketts MD, Marmorstein R. Dissecting the molecular roles of histone chaperones in histone acetylation by type $B$ histone acetyltransferases (HAT-B). J Biol Chem. 2015;290:30648-57.

33. Hilfiker A, Hilfiker-Kleiner D, Pannuti A, Lucchesi JC. Mof, a putative acetyl transferase gene related to the Tip60 and MOZ human genes and to the SAS genes of yeast, is required for dosage compensation in Drosophila. EMBO J. 1997;16:2054-60.

34. Cai Y, Jin J, Swanson SK, Cole MD, Choi SH, Florens L, Washburn MP, Conaway JW, Conaway RC. Subunit composition and substrate specificity of a MOF-containing histone acetyltransferase distinct from the male-specific lethal (MSL) complex. J Biol Chem. 2010;285:4268-72.

35. Smith ER, Pannuti A, Gu W, Steurnagel A, Cook RG, Allis CD, Lucchesi JC. The drosophila MSL complex acetylates histone $\mathrm{H} 4$ at lysine 16 , a chromatin modification linked to dosage compensation. Mol Cell Biol. 2000;20:312-8.

36. Mendjan S, Taipale M, Kind J, Holz H, Gebhardt P, Schelder M, Vermeulen M, Buscaino A, Duncan K, Mueller J, et al. Nuclear pore components are involved in the transcriptional regulation of dosage compensation in Drosophila. Mol Cell. 2006;21:811-23.

37. Smith ER, Cayrou C, Huang R, Lane WS, Cote J, Lucchesi JC. A human protein complex homologous to the Drosophila MSL complex is responsible for the majority of histone $\mathrm{H} 4$ acetylation at lysine 16 . Mol Cell Biol. 2005;25:9175-88.

38. Liu N, Zhang R, Zhao X, Su J, Bian X, Ni J, Yue Y, Cai Y, Jin J. A potential diagnostic marker for ovarian cancer: involvement of the histone acetyltransferase, human males absent on the first. Oncol Lett. 2013;6:393-400.

39. Pfister S, Rea S, Taipale M, Mendrzyk F, Straub B, Ittrich C, Thuerigen O, Sinn HP, Akhtar A, Lichter P. The histone acetyltransferase hMOF is frequently downregulated in primary breast carcinoma and medulloblastoma and constitutes a biomarker for clinical outcome in medulloblastoma. Int 」 Cancer. 2008;122:1207-13.

40. Wang Y, Zhang R, Wu D, Lu Z, Sun W, Cai Y, Wang C, Jin J. Epigenetic change in kidney tumor: downregulation of histone acetyltransferase MYST1 in human renal cell carcinoma. J Exp Clin Cancer Res. 2013;32:8.

41. Cao L, Zhu L, Yang J, Su J, Ni J, Du Y, Liu D, Wang Y, Wang F, Jin J, Cai Y. Correlation of low expression of hMOF with clinicopathological features of colorectal carcinoma, gastric cancer and renal cell carcinoma. Int J Oncol. 2014:44:1207-14

42. Zhao L, Wang DL, Liu Y, Chen S, Sun FL. Histone acetyltransferase hMOF promotes $S$ phase entry and tumorigenesis in lung cancer. Cell Signal. 2013;25:1689-98.

43. Cai M, Hu Z, Liu J, Gao J, Tan M, Zhang D, Zhu L, Liu S, Hou R, Lin B. Expression of hMOF in different ovarian tissues and its effects on ovarian cancer prognosis. Oncol Rep. 2015;33:685-92.

44. Kubler K, Arndt PF, Wardelmann E, Landwehr C, Krebs D, Kuhn W, van der Ven K. Genetic alterations of HLA-class II in ovarian cancer. Int J Cancer. 2008;123:1350-6.

45. Kulski JK, Dawkins RL. The P5 multicopy gene family in the MHC is related in sequence to human endogenous retroviruses HERV-L and HERV-16. Immunogenetics. 1999;49:404-12.
46. Gregoretti IV, Lee YM, Goodson HV. Molecular evolution of the histone deacetylase family: functional implications of phylogenetic analysis. J Mol Biol. 2004;338:17-31.

47. Wang Y, Stowe RL, Pinello CE, Tian G, Madoux F, Li D, Zhao LY, Li JL, Wang $Y$, Wang $Y$, et al. Identification of histone deacetylase inhibitors with benzoylhydrazide scaffold that selectively inhibit class I histone deacetylases. Chem Biol. 2015;22:273-84.

48. Yang XJ, Seto E. The Rpd3/Hda1 family of lysine deacetylases: from bacteria and yeast to mice and men. Nat Rev Mol Cell Biol. 2008;9:206-18.

49. Smith BC, Hallows WC, Denu JM. Mechanisms and molecular probes of sirtuins. Chem Biol. 2008;15:1002-13.

50. Khabele D, Son DS, Parl AK, Goldberg GL, Augenlicht LH, Mariadason JM, Rice VM. Drug-induced inactivation or gene silencing of class I histone deacetylases suppresses ovarian cancer cell growth: implications for therapy. Cancer Biol Ther. 2007;6:795-801.

51. Weichert W, Denkert C, Noske A, Darb-Esfahani S, Dietel M, Kalloger SE, Huntsman DG, Kobel M. Expression of class I histone deacetylases indicates poor prognosis in endometrioid subtypes of ovarian and endometrial carcinomas. Neoplasia. 2008;10:1021-7.

52. Cacan E. Epigenetic regulation of RGS2 (regulator of G-protein signaling 2) in chemoresistant ovarian cancer cells. J Chemother. 2017;29:173-8.

53. Hooks SB, Callihan P, Altman MK, Hurst JH, Ali MW, Murph MM. Regulators of G-protein signaling RGS10 and RGS17 regulate chemoresistance in ovarian cancer cells. Mol Cancer. 2010;9:289.

54. Hayashi A, Horiuchi A, Kikuchi N, Hayashi T, Fuseya C, Suzuki A, Konishi I, Shiozawa T. Type-specific roles of histone deacetylase (HDAC) overexpression in ovarian carcinoma: HDAC1 enhances cell proliferation and HDAC3 stimulates cell migration with downregulation of E-cadherin. Int J Cancer. 2010;127:1332-46.

55. Kober J, Leitner J, Klauser C, Woitek R, Majdic O, Stockl J, HerndlerBrandstetter D, Grubeck-Loebenstein B, Reipert BM, PickI WF, et al. The capacity of the TNF family members 4-1BBL, OX40L, CD70, GITRL, CD30L and LIGHT to costimulate human T cells. Eur J Immunol. 2008;38:2678-88.

56. Cacan E. Epigenetic-mediated immune suppression of positive costimulatory molecules in chemoresistant ovarian cancer cells. Cell Biol Int. 2017:41:328-39.

57. Zhang L, Conejo-Garcia JR, Katsaros D, Gimotty PA, Massobrio M, Regnani G, Makrigiannakis A, Gray H, Schlienger K, Liebman MN, et al. Intratumoral T cells, recurrence, and survival in epithelial ovarian cancer. N Engl J Med. 2003;348:203-13.

58. Hwang WT, Adams SF, Tahirovic E, Hagemann IS, Coukos G. Prognostic significance of tumor-infiltrating $T$ cells in ovarian cancer: a meta-analysis. Gynecol Oncol. 2012;124:192-8.

59. Peper JK, Bosmuller HC, Schuster H, Guckel B, Horzer H, Roehle K, Schafer R, Wagner P, Rammensee HG, Stevanovic S, et al. HLA ligandomics identifies histone deacetylase 1 as target for ovarian cancer immunotherapy. Oncoimmunology. 2016;5:e1065369.

60. Witt AE, Lee CW, Lee TI, Azzam DJ, Wang B, Caslini C, Petrocca F, Grosso J, Jones $\mathrm{M}$, Cohick EB, et al. Identification of a cancer stem cell-specific function for the histone deacetylases, HDAC1 and HDAC7, in breast and ovarian cancer. Oncogene. 2017;36:1707-20.

61. Shen YF, Wei AM, Kou Q, Zhu QY, Zhang L. Histone deacetylase 4 increases progressive epithelial ovarian cancer cells via repression of p21 on fibrillar collagen matrices. Oncol Rep. 2016;35:948-54.

62. Kotian S, Liyanarachchi S, Zelent A, Parvin JD. Histone deacetylases 9 and 10 are required for homologous recombination. J Biol Chem. 2011;286:7722-6.

63. Islam MM, Banerjee T, Packard CZ, Kotian S, Selvendiran K, Cohn DE, Parvin JD. HDAC10 as a potential therapeutic target in ovarian cancer. Gynecol Oncol. 2017:144:613-20.

64. Hannan A, Abraham NM, Goyal S, Jamir I, Priyakumar UD, Mishra K. Sumoylation of Sir2 differentially regulates transcriptional silencing in yeast. Nucleic Acids Res. 2015:43:10213-26.

65. Imai S, Armstrong CM, Kaeberlein M, Guarente L. Transcriptional silencing and longevity protein $\mathrm{Sir} 2$ is an NAD-dependent histone deacetylase. Nature. 2000;403:795-800.

66. Landry J, Sutton A, Tafrov ST, Heller RC, Stebbins J, Pillus L, Sternglanz R. The silencing protein SIR2 and its homologs are NAD-dependent protein deacetylases. Proc Natl Acad Sci U S A. 2000;97:5807-11.

67. Boily G, Seifert EL, Bevilacqua L, He XH, Sabourin G, Estey C, Moffat C, Crawford S, Saliba S, Jardine K, et al. SirT1 regulates energy metabolism and response to caloric restriction in mice. PLoS One. 2008;3:e1759. 
68. Lin SJ, Defossez PA, Guarente L. Requirement of NAD and SIR2 for life-span extension by calorie restriction in Saccharomyces cerevisiae. Science. 2000; 289:2126-8.

69. Luo J, Nikolaev AY, Imai S, Chen D, Su F, Shiloh A, Guarente L, Gu W. Negative control of p53 by Sir2alpha promotes cell survival under stress. Cell. 2001;107:137-48.

70. Michishita E, Park JY, Burneskis JM, Barrett JC, Horikawa I. Evolutionarily conserved and nonconserved cellular localizations and functions of human SIRT proteins. Mol Biol Cell. 2005;16:4623-35.

71. Haigis MC, Guarente LP. Mammalian sirtuins--emerging roles in physiology, aging, and calorie restriction. Genes Dev. 2006;20:2913-21.

72. Vaquero A, Scher M, Lee D, Erdjument-Bromage H, Tempst P, Reinberg D. Human SirT1 interacts with histone $\mathrm{H} 1$ and promotes formation of facultative heterochromatin. Mol Cell. 2004;16:93-105.

73. Vaquero A, Scher M, Erdjument-Bromage H, Tempst P, Serrano L, Reinberg D. SIRT1 regulates the histone methyl-transferase SUV39H1 during heterochromatin formation. Nature. 2007:450:440-4.

74. Motta MC, Divecha N, Lemieux M, Kamel C, Chen D, Gu W, Bultsma Y, McBurney M, Guarente L. Mammalian SIRT1 represses forkhead transcription factors. Cell. 2004;116:551-63.

75. Nemoto S, Fergusson MM, Finkel T. SIRT1 functionally interacts with the metabolic regulator and transcriptional coactivator PGC-1\{alpha\}. J Biol Chem. 2005;280:16456-60.

76. Picard F, Kurtev M, Chung N, Topark-Ngarm A, Senawong T, Machado De Oliveira R, Leid M, McBurney MW, Guarente L. Sirt1 promotes fat mobilization in white adipocytes by repressing PPAR-gamma. Nature. 2004;429:771-6.

77. Ford J, Jiang M, Milner J. Cancer-specific functions of SIRT1 enable human epithelial cancer cell growth and survival. Cancer Res. 2005;65:10457-63.

78. Lee JT, Gu W. SIRT1: regulator of p53 deacetylation. Genes Cancer. 2013;4: $112-7$.

79. Jang KY, Kim KS, Hwang SH, Kwon KS, Kim KR, Park HS, Park BH, Chung MJ, Kang MJ, Lee DG, Moon WS. Expression and prognostic significance of SIRT1 in ovarian epithelial tumours. Pathology. 2009;41:366-71.

80. Sun L, Li H, Chen J, Iwasaki Y, Kubota T, Matsuoka M, Shen A, Chen Q, Xu Y. PIASy mediates hypoxia-induced SIRT1 transcriptional repression and epithelial-to-mesenchymal transition in ovarian cancer cells. J Cell Sci. 2013; 126:3939-47.

81. Cao B, Shi Q, Wang W. Higher expression of SIRT1 induced resistance of esophageal squamous cell carcinoma cells to cisplatin. J Thorac Dis. 2015;7:711-9.

82. Wang Z, Chen W. Emerging roles of SIRT1 in Cancer drug resistance. Genes Cancer. 2013;4:82-90.

83. Li D, Bi FF, Chen NN, Cao JM, Sun WP, Zhou YM, Li CY, Yang Q. A novel crosstalk between BRCA1 and sirtuin 1 in ovarian cancer. Sci Rep. 2014;4:6666.

84. Li D, Wu QJ, Bi FF, Chen SL, Zhou YM, Zhao Y, Yang Q. Effect of the BRCA1-SIRT1-EGFR axis on cisplatin sensitivity in ovarian cancer. Am J Transl Res. 2016:8:1601-8.

85. Shuang T, Wang M, Zhou Y, Shi C. Over-expression of Sirt1 contributes to chemoresistance and indicates poor prognosis in serous epithelial ovarian cancer (EOC). Med Oncol. 2015:32:260.

86. Alhazzazi TY, Kamarajan P, Verdin E, Kapila YL. SIRT3 and cancer: tumor promoter or suppressor? Biochim Biophys Acta. 2011;1816:80-8.

87. Dong XC, Jing LM, Wang WX, Gao YX. Down-regulation of SIRT3 promotes ovarian carcinoma metastasis. Biochem Biophys Res Commun. 2016;475: 245-50

88. Xiang XY, Kang JS, Yang XC, Su J, Wu Y, Yan XY, Xue YN, Xu Y, Liu YH, Yu CY, et al. SIRT3 participates in glucose metabolism interruption and apoptosis induced by BH3 mimetic S1 in ovarian cancer cells. Int J Oncol. 2016:49:773-84.

89. Marquardt JU, Fischer K, Baus K, Kashyap A, Ma S, Krupp M, Linke M, Teufel A, Zechner U, Strand D, et al. Sirtuin-6-dependent genetic and epigenetic alterations are associated with poor clinical outcome in hepatocellular carcinoma patients. Hepatology. 2013;58:1054-64.

90. Sebastian C, Zwaans BM, Silberman DM, Gymrek M, Goren A, Zhong L, Ram O, Truelove J, Guimaraes AR, Toiber D, et al. The histone deacetylase SIRT6 is a tumor suppressor that controls cancer metabolism. Cell. 2012;151:1185-99.

91. Khongkow M, Olmos Y, Gong C, Gomes AR, Monteiro LJ, Yague E, Cavaco TB, Khongkow P, Man EP, Laohasinnarong S, et al. SIRT6 modulates paclitaxel and epirubicin resistance and survival in breast cancer. Carcinogenesis. 2013;34:1476-86.

92. Zhang G, Liu Z, Qin S, Li K. Decreased expression of SIRT6 promotes tumor cell growth correlates closely with poor prognosis of ovarian cancer. Eur J Gynaecol Oncol. 2015;36:629-32.
93. Lachner M, O'Sullivan RJ, Jenuwein T. An epigenetic road map for histone lysine methylation. J Cell Sci. 2003;116:2117-24.

94. Martin C, Zhang Y. The diverse functions of histone lysine methylation. Nat Rev Mol Cell Biol. 2005;6:838-49.

95. Kouzarides T. Histone methylation in transcriptional control. Curr Opin Genet Dev. 2002;12:198-209.

96. Copeland RA, Solomon ME, Richon VM. Protein methyltransferases as a target class for drug discovery. Nat Rev Drug Discov. 2009;8:724-32.

97. Barski A, Cuddapah S, Cui K, Roh TY, Schones DE, Wang Z, Wei G, Chepelev I, Zhao K. High-resolution profiling of histone methylations in the human genome. Cell. 2007;129:823-37.

98. Taverna SD, Li H, Ruthenburg AJ, Allis CD, Patel DJ. How chromatin-binding modules interpret histone modifications: lessons from professional pocket pickers. Nat Struct Mol Biol. 2007;14:1025-40.

99. Tsukada Y, Fang J, Erdjument-Bromage H, Warren ME, Borchers $\mathrm{CH}$, Tempst $P$, Zhang $Y$. Histone demethylation by a family of JmjC domain-containing proteins. Nature. 2006:439:811-6.

100. Greer EL, Shi Y. Histone methylation: a dynamic mark in health, disease and inheritance. Nat Rev Genet. 2012;13:343-57.

101. Albert M, Helin K. Histone methyltransferases in cancer. Semin Cell Dev Biol. 2010;21:209-20

102. Chi $P$, Allis CD, Wang GG. Covalent histone modifications--miswritten, misinterpreted and mis-erased in human cancers. Nat Rev Cancer. 2010;10:457-69.

103. Tian X, Fang J. Current perspectives on histone demethylases. Acta Biochim Biophys Sin Shanghai. 2007:39:81-8.

104. Chapman-Rothe N, Curry E, Zeller C, Liber D, Stronach E, Gabra H, GhaemMaghami S, Brown R. Chromatin H3K27me3/H3K4me3 histone marks define gene sets in high-grade serous ovarian cancer that distinguish malignant, tumour-sustaining and chemo-resistant ovarian tumour cells. Oncogene. 2013;32:4586-92.

105. Morera L, Lubbert M, Jung M. Targeting histone methyltransferases and demethylases in clinical trials for cancer therapy. Clin Epigenetics. 2016;8:57.

106. Jenuwein T, Laible G, Dorn R, Reuter G. SET domain proteins modulate chromatin domains in eu- and heterochromatin. Cell Mol Life Sci. 1998;54: 80-93.

107. Dillon SC, Zhang X, Trievel RC, Cheng X. The SET-domain protein superfamily: protein lysine methyltransferases. Genome Biol. 2005;6:227.

108. Peters AH, O'Carroll D, Scherthan H, Mechtler K, Sauer S, Schofer C, Weipoltshammer K, Pagani M, Lachner M, Kohlmaier A, et al. Loss of the Suv39h histone methyltransferases impairs mammalian heterochromatin and genome stability. Cell. 2001;107:323-37.

109. Ontoso D, Acosta I, van Leeuwen F, Freire R, San-Segundo PA. Dot1dependent histone H3K79 methylation promotes activation of the Mek1 meiotic checkpoint effector kinase by regulating the Hop1 adaptor. PLoS Genet. 2013:9:e1003262

110. Akter KA, Mansour MA, Hyodo T, Ito S, Hamaguchi M, Senga T. FAM98A is a novel substrate of PRMT1 required for tumor cell migration, invasion, and colony formation. Tumour Biol. 2016;37:4531-9.

111. Poulard C, Corbo L, Le Romancer M. Protein arginine methylation/ demethylation and cancer. Oncotarget. 2016;7:67532-50.

112. Zurita-Lopez Cl, Sandberg T, Kelly R, Clarke SG. Human protein arginine methyltransferase 7 (PRMT7) is a type III enzyme forming omega-NGmonomethylated arginine residues. J Biol Chem. 2012;287:7859-70.

113. Eram MS, Shen Y, Szewczyk MM, Wu H, Senisterra G, Li F, Butler KV, Kaniskan HU, Speed BA, dela Sena C, et al. A potent, selective, and cell-active inhibitor of human type I protein arginine methyltransferases. ACS Chem Biol. 2016;11:772-81.

114. Czermin B, Melfi R, McCabe D, Seitz V, Imhof A, Pirrotta V. Drosophila enhancer of Zeste/ESC complexes have a histone $\mathrm{H} 3$ methyltransferase activity that marks chromosomal Polycomb sites. Cell. 2002;111:185-96.

115. Muller J, Hart CM, Francis NJ, Vargas ML, Sengupta A, Wild B, Miller EL, O'Connor MB, Kingston RE, Simon JA. Histone methyltransferase activity of a Drosophila Polycomb group repressor complex. Cell. 2002;111:197-208.

116. Vire E, Brenner C, Deplus R, Blanchon L, Fraga M, Didelot C, Morey L, Van Eynde A, Bernard D, Vanderwinden JM, et al. The Polycomb group protein EZH2 directly controls DNA methylation. Nature. 2006:439:871-4.

117. Schuettengruber B, Chourrout D, Vervoort M, Leblanc B, Cavalli G. Genome regulation by polycomb and trithorax proteins. Cell. 2007;128:735-45.

118. Kuzmichev A, Jenuwein T, Tempst P, Reinberg D. Different EZH2-containing complexes target methylation of histone $\mathrm{H} 1$ or nucleosomal histone $\mathrm{H} 3$. Mol Cell. 2004;14:183-93. 
119. Deb G, Singh AK, Gupta S. EZH2: not EZHY (easy) to deal. Mol Cancer Res. 2014;12:639-53.

120. Xu K, Wu ZJ, Groner AC, He HH, Cai C, Lis RT, Wu X, Stack EC, Loda M, Liu T, et al. EZH2 oncogenic activity in castration-resistant prostate cancer cells is Polycomb-independent. Science. 2012;338:1465-9.

121. Shi B, Liang J, Yang X, Wang Y, Zhao Y, Wu H, Sun L, Zhang Y, Chen Y, Li R, et al. Integration of estrogen and Wnt signaling circuits by the polycomb group protein EZH2 in breast cancer cells. Mol Cell Biol. 2007;27:5105-19.

122. Gonzalez ME, Moore HM, Li X, Toy KA, Huang W, Sabel MS, Kidwell KM, Kleer CG. EZH2 expands breast stem cells through activation of NOTCH1 signaling. Proc Natl Acad Sci U S A. 2014;111:3098-103.

123. Simon JA, Lange CA. Roles of the EZH2 histone methyltransferase in cancer epigenetics. Mutat Res. 2008;647:21-9.

124. Jones BA, Varambally S, Arend RC. Histone methyltransferase EZH2: a therapeutic target for ovarian Cancer. Mol Cancer Ther. 2018;17:591-602.

125. Rizzo S, Hersey JM, Mellor P, Dai W, Santos-Silva A, Liber D, Luk L, Titley I, Carden $C P$, Box G, et al. Ovarian cancer stem cell-like side populations are enriched following chemotherapy and overexpress EZH2. Mol Cancer Ther 2011:10:325-35.

126. Hu S, Yu L, Li Z, Shen Y, Wang J, Cai J, Xiao L, Wang Z. Overexpression of EZH2 contributes to acquired cisplatin resistance in ovarian cancer cells in vitro and in vivo. Cancer Biol Ther. 2010;10:788-95.

127. Li T, Cai J, Ding H, Xu L, Yang Q, Wang Z. EZH2 participates in malignant biological behavior of epithelial ovarian cancer through regulating the expression of BRCA1. Cancer Biol Ther. 2014;15:271-8

128. Hollis RL, Churchman M, Gourley C. Distinct implications of different BRCA mutations: efficacy of cytotoxic chemotherapy, PARP inhibition and clinical outcome in ovarian cancer. Onco Targets Ther. 2017;10:2539-51.

129. Rao ZY, Cai MY, Yang GF, He LR, Mai SJ, Hua WF, Liao YJ, Deng HX, Chen YC, Guan XY, et al. EZH2 supports ovarian carcinoma cell invasion and/or metastasis via regulation of TGF-beta1 and is a predictor of outcome in ovarian carcinoma patients. Carcinogenesis. 2010;31:1576-83.

130. Xu L, Deng Q, Pan Y, Peng M, Wang X, Song L, Xiao M, Wang Z. Cancerassociated fibroblasts enhance the migration ability of ovarian cancer cells by increasing EZH2 expression. Int J Mol Med. 2014;33:91-6.

131. Feng Q, Wang $\mathrm{H}, \mathrm{Ng} \mathrm{HH}$, Erdjument-Bromage $\mathrm{H}$, Tempst $\mathrm{P}$, Struhl K, Zhang Y. Methylation of H3-lysine 79 is mediated by a new family of HMTases without a SET domain. Curr Biol. 2002:12:1052-8.

132. Nguyen AT, Zhang Y. The diverse functions of Dot1 and H3K79 methylation. Genes Dev. 2011:25:1345-58.

133. Zhang X, Liu D, Li M, Cao C, Wan D, Xi B, Li W, Tan J, Wang J, Wu Z, et al. Prognostic and therapeutic value of disruptor of telomeric silencing-1-like (DOT1L) expression in patients with ovarian cancer. J Hematol Oncol. 2017;10:29.

134. Guo A, Gu H, Zhou J, Mulhern D, Wang Y, Lee KA, Yang V, Aguiar M, Kornhauser J, Jia X, et al. Immunoaffinity enrichment and mass spectrometry analysis of protein methylation. Mol Cell Proteomics. 2014;13:372-87.

135. Wei $H$, Mundade $R$, Lange $K C$, Lu T. Protein arginine methylation of non-histone proteins and its role in diseases. Cell Cycle. 2014;13:32-41.

136. Wang $H$, Huang ZQ, Xia L, Feng Q, Erdjument-Bromage $H$, Strahl BD, Briggs $\mathrm{SD}$, Allis CD, Wong J, Tempst P, Zhang Y. Methylation of histone $\mathrm{H} 4$ at arginine 3 facilitating transcriptional activation by nuclear hormone receptor. Science. 2001;293:853-7.

137. Mathioudaki K, Scorilas A, Ardavanis A, Lymberi P, Tsiambas E, Devetzi M Apostolaki A, Talieri M. Clinical evaluation of PRMT1 gene expression in breast cancer. Tumour Biol. 2011:32:575-82.

138. Seligson DB, Horvath S, Shi T, Yu H, Tze S, Grunstein M, Kurdistani SK. Global histone modification patterns predict risk of prostate cancer recurrence. Nature. 2005;435:1262-6.

139. Branscombe TL, Frankel A, Lee JH, Cook JR, Yang Z, Pestka S, Clarke S. PRMT5 (Janus kinase-binding protein 1) catalyzes the formation of symmetric dimethylarginine residues in proteins. J Biol Chem. 2001;276: 32971-6.

140. Mallappa C, Hu YJ, Shamulailatpam P, Tae S, Sif S, Imbalzano AN. The expression of myogenic microRNAs indirectly requires protein arginine methyltransferase (Prmt)5 but directly requires Prmt4. Nucleic Acids Res. 2011;39:1243-55

141. Scoumanne A, Zhang J, Chen X. PRMT5 is required for cell-cycle progression and p53 tumor suppressor function. Nucleic Acids Res. 2009;37:4965-76.

142. Cho EC, Zheng S, Munro S, Liu G, Carr SM, Moehlenbrink J, Lu YC, Stimson $\mathrm{L}$, Khan $\mathrm{O}$, Konietzny R, et al. Arginine methylation controls growth regulation by E2F-1. EMBO J. 2012;31:1785-97.
143. Pal S, Vishwanath SN, Erdjument-Bromage H, Tempst P, Sif S. Human SWI/ SNF-associated PRMT5 methylates histone $\mathrm{H} 3$ arginine 8 and negatively regulates expression of ST7 and NM23 tumor suppressor genes. Mol Cell Biol. 2004;24:9630-45.

144. Fabbrizio E, El Messaoudi S, Polanowska J, Paul C, Cook JR, Lee JH, Negre V, Rousset M, Pestka S, Le Cam A, Sardet C. Negative regulation of transcription by the type II arginine methyltransferase PRMT5. EMBO Rep. 2002;3:641-5.

145. Hou Z, Peng H, Ayyanathan K, Yan KP, Langer EM, Longmore GD, Rauscher FJ 3rd. The LIM protein AJUBA recruits protein arginine methyltransferase 5 to mediate SNAIL-dependent transcriptional repression. Mol Cell Biol. 2008; 28:3198-207.

146. Bao X, Zhao S, Liu T, Liu Y, Liu Y, Yang X. Overexpression of PRMT5 promotes tumor cell growth and is associated with poor disease prognosis in epithelial ovarian cancer. J Histochem Cytochem. 2013;61:206-17.

147. Polager S, Ginsberg D. E2F - at the crossroads of life and death. Trends Cell Biol. 2008; 18:528-35

148. Shi Y, Lan F, Matson C, Mulligan P, Whetstine JR, Cole PA, Casero RA, Shi Y. Histone demethylation mediated by the nuclear amine oxidase homolog LSD1. Cell. 2004;119:941-53.

149. Hou H, Yu H. Structural insights into histone lysine demethylation. Curr Opin Struct Biol. 2010:20:739-48.

150. Cloos PA, Christensen J, Agger K, Helin K. Erasing the methyl mark: histone demethylases at the center of cellular differentiation and disease. Genes Dev. 2008;22:1115-40.

151. Wang Y, Wysocka J, Sayegh J, Lee YH, Perlin JR, Leonelli L, Sonbuchner LS, McDonald CH, Cook RG, Dou Y, et al. Human PAD4 regulates histone arginine methylation levels via demethylimination. Science. 2004;306:279-83.

152. Chang B, Chen Y, Zhao Y, Bruick RK. JMJD6 is a histone arginine demethylase. Science. 2007:318:444-7.

153. Kwok J, O'Shea M, Hume DA, Lengeling A. Jmjd6, a JmjC dioxygenase with many interaction partners and pleiotropic functions. Front Genet. 2017;8:32.

154. Yang M, Gocke CB, Luo X, Borek D, Tomchick DR, Machius M, Otwinowski Z, Yu H. Structural basis for CoREST-dependent demethylation of nucleosomes by the human LSD1 histone demethylase. Mol Cell. 2006;23:377-87.

155. Metzger E, Wissmann M, Yin N, Muller JM, Schneider R, Peters AH, Gunther T, Buettner R, Schule R. LSD1 demethylates repressive histone marks to promote androgen-receptor-dependent transcription. Nature. 2005;437:436-9.

156. Garcia-Bassets I, Kwon YS, Telese F, Prefontaine GG, Hutt KR, Cheng CS, Ju BG, Ohgi KA, Wang J, Escoubet-Lozach L, et al. Histone methylationdependent mechanisms impose ligand dependency for gene activation by nuclear receptors. Cell. 2007;128:505-18.

157. Wang J, Hevi S, Kurash JK, Lei H, Gay F, Bajko J, Su H, Sun W, Chang H, Xu $\mathrm{G}$, et al. The lysine demethylase LSD1 (KDM1) is required for maintenance of global DNA methylation. Nat Genet. 2009;41:125-9.

158. Huang J, Sengupta R, Espejo AB, Lee MG, Dorsey JA, Richter M, Opravil S, Shiekhattar R, Bedford MT, Jenuwein T, Berger SL. p53 is regulated by the lysine demethylase LSD1. Nature. 2007;449:105-8.

159. Ding J, Zhang ZM, Xia Y, Liao GQ, Pan Y, Liu S, Zhang Y, Yan ZS. LSD1mediated epigenetic modification contributes to proliferation and metastasis of colon cancer. Br J Cancer. 2013;109:994-1003.

160. Derr RS, van Hoesel AQ, Benard A, Goossens-Beumer IJ, Sajet A, DekkerEnsink NG, de Kruijf EM, Bastiaannet E, Smit VT, van de Velde CJ, Kuppen PJ. High nuclear expression levels of histone-modifying enzymes LSD1, HDAC2 and SIRT1 in tumor cells correlate with decreased survival and increased relapse in breast cancer patients. BMC Cancer. 2014;14:604.

161. Suikki HE, Kujala PM, Tammela TL, van Weerden WM, Vessella RL, Visakorpi T. Genetic alterations and changes in expression of histone demethylases in prostate cancer. Prostate. 2010;70:889-98.

162. Lv T, Yuan D, Miao X, Lv Y, Zhan P, Shen X, Song Y. Over-expression of LSD1 promotes proliferation, migration and invasion in non-small cell lung cancer. PLoS One. 2012;7:e35065.

163. Zhao ZK, Yu HF, Wang DR, Dong P, Chen L, Wu WG, Ding WJ, Liu YB. Overexpression of lysine specific demethylase 1 predicts worse prognosis in primary hepatocellular carcinoma patients. World J Gastroenterol. 2012;18:6651-6.

164. Hayami S, Kelly JD, Cho HS, Yoshimatsu M, Unoki M, Tsunoda T, Field HI, Neal DE, Yamaue H, Ponder BA, et al. Overexpression of LSD1 contributes to human carcinogenesis through chromatin regulation in various cancers. Int J Cancer. 2011;128:574-86.

165. Bradley C, van der Meer R, Roodi N, Yan H, Chandrasekharan MB, Sun ZW, Mernaugh RL, Parl FF. Carcinogen-induced histone alteration in normal human mammary epithelial cells. Carcinogenesis. 2007;28:2184-92. 
166. Konovalov S, Garcia-Bassets I. Analysis of the levels of lysine-specific demethylase 1 (LSD1) mRNA in human ovarian tumors and the effects of chemical LSD1 inhibitors in ovarian cancer cell lines. J Ovarian Res. 2013;6:75.

167. Chen C, Ge J, Lu Q, Ping G, Yang C, Fang X. Expression of lysine-specific demethylase 1 in human epithelial ovarian cancer. J Ovarian Res. 2015;8:28.

168. Li Y, Wan X, Wei Y, Liu X, Lai W, Zhang L, Jin J, Wu C, Shao Q, Shao G, Lin Q. LSD1-mediated epigenetic modification contributes to ovarian cancer cell migration and invasion. Oncol Rep. 2016;35:3586-92.

169. Shao G, Wang J, Li Y, Liu X, Xie X, Wan X, Yan M, Jin J, Lin Q, Zhu H, et al. Lysine-specific demethylase 1 mediates epidermal growth factor signaling to promote cell migration in ovarian cancer cells. Sci Rep. 2015;5:15344.

170. Lin T, Ponn A, Hu X, Law BK, Lu J. Requirement of the histone demethylase LSD1 in Snai1-mediated transcriptional repression during epithelialmesenchymal transition. Oncogene. 2010;29:4896-904.

171. Ben-Porath I, Thomson MW, Carey VJ, Ge R, Bell GW, Regev A, Weinberg RA. An embryonic stem cell-like gene expression signature in poorly differentiated aggressive human tumors. Nat Genet. 2008:40:499-507.

172. Peng S, Maihle NJ, Huang Y. Pluripotency factors Lin 28 and Oct4 identify a subpopulation of stem cell-like cells in ovarian cancer. Oncogene. 2010;29:2153-9.

173. Zhang X, Lu F, Wang J, Yin F, Xu Z, Qi D, Wu X, Cao Y, Liang W, Liu Y, et al. Pluripotent stem cell protein Sox2 confers sensitivity to LSD1 inhibition in cancer cells. Cell Rep. 2013;5:445-57.

174. Lafky JM, Wilken JA, Baron AT, Maihle NJ. Clinical implications of the ErbB/ epidermal growth factor (EGF) receptor family and its ligands in ovarian cancer. Biochim Biophys Acta. 2008;1785:232-65.

175. Psyrri A, Kassar M, Yu Z, Bamias A, Weinberger PM, Markakis S, Kowalski D, Camp RL, Rimm DL, Dimopoulos MA. Effect of epidermal growth factor receptor expression level on survival in patients with epithelial ovarian cancer. Clin Cancer Res. 2005;11:8637-43.

176. Lassus H, Sihto H, Leminen A, Joensuu H, Isola J, Nupponen NN, Butzow R. Gene amplification, mutation, and protein expression of EGFR and mutations of ERBB2 in serous ovarian carcinoma. J Mol Med (Berl). 2006;84:671-81.

177. Yamane K, Toumazou C, Tsukada Y, Erdjument-Bromage H, Tempst P, Wong J, Zhang Y. JHDM2A, a JmjC-containing H3K9 demethylase, facilitates transcription activation by androgen receptor. Cell. 2006;125:483-95.

178. Li J, Yu B, Deng P, Cheng Y, Yu Y, Kevork K, Ramadoss S, Ding X, Li X, Wang CY. KDM3 epigenetically controls tumorigenic potentials of human colorectal cancer stem cells through Wnt/beta-catenin signalling. Nat Commun. 2017:8:15146.

179. Nakatsuka T, Tateishi K, Kudo Y, Yamamoto K, Nakagawa H, Fujiwara H, Takahashi R, Miyabayashi K, Asaoka Y, Tanaka Y, et al. Impact of histone demethylase KDM3A-dependent AP-1 transactivity on hepatotumorigenesis induced by PI3K activation. Oncogene. 2017;36(45):6262-71.

180. Ramadoss S, Guo G, Wang CY. Lysine demethylase KDM3A regulates breast cancer cell invasion and apoptosis by targeting histone and the nonhistone protein p53. Oncogene. 2017;36:47-59.

181. Sechler M, Parrish JK, Birks DK, Jedlicka P. The histone demethylase KDM3A, and its downstream target MCAM, promote Ewing sarcoma cell migration and metastasis. Oncogene. 2017;36:4150-60.

182. Ramadoss S, Sen S, Ramachandran I, Roy S, Chaudhuri G, Farias-Eisner R. Lysine-specific demethylase KDM3A regulates ovarian cancer stemness and chemoresistance. Oncogene. 2017;36:1537-45.

183. Hillringhaus L, Yue WW, Rose NR, Ng SS, Gileadi C, Loenarz C, Bello SH, Bray JE, Schofield CJ, Oppermann U. Structural and evolutionary basis for the dual substrate selectivity of human KDM4 histone demethylase family. J Biol Chem. 2011;286:41616-25.

184. Katoh Y, Katoh M. Comparative integromics on JMJD2A, JMJD2B and JMJD2C: preferential expression of JMJD2C in undifferentiated ES cells. Int J Mol Med. 2007;20:269-73.

185. Wilson C, Qiu L, Hong Y, Karnik T, Tadros G, Mau B, Ma T, Mu Y, New J, Louie RJ, et al. The histone demethylase KDM4B regulates peritoneal seeding of ovarian cancer. Oncogene. 2017;36:2565-76.

186. Semenza GL. Hypoxia-inducible factors: mediators of cancer progression and targets for cancer therapy. Trends Pharmacol Sci. 2012;33:207-14.

187. Birner P, Schindl M, Obermair A, Breitenecker G, Oberhuber G. Expression of hypoxia-inducible factor 1alpha in epithelial ovarian tumors: its impact on prognosis and on response to chemotherapy. Clin Cancer Res. 2001;7:1661-8.

188. Chi JT, Wang Z, Nuyten DS, Rodriguez EH, Schaner ME, Salim A, Wang Y, Kristensen GB, Helland A, Borresen-Dale AL, et al. Gene expression programs in response to hypoxia: cell type specificity and prognostic significance in human cancers. PLoS Med. 2006:3:e47.
189. Moniz S, Biddlestone J, Rocha S. Grow(2): the HIF system, energy homeostasis and the cell cycle. Histol Histopathol. 2014;29:589-600.

190. Beyer S, Kristensen MM, Jensen KS, Johansen JV, Staller P. The histone demethylases JMJD1A and JMJD2B are transcriptional targets of hypoxiainducible factor HIF. J Biol Chem. 2008;283:36542-52.

191. Shin S, Janknecht R. Activation of androgen receptor by histone demethylases JMJD2A and JMJD2D. Biochem Biophys Res Commun. 2007;359:742-6.

192. Berry WL, Shin S, Lightfoot SA, Janknecht R. Oncogenic features of the JMJD2A histone demethylase in breast cancer. Int J Oncol. 2012;41:1701-6.

193. Black JC, Manning AL, Van Rechem C, Kim J, Ladd B, Cho J, Pineda CM, Murphy N, Daniels DL, Montagna C, et al. KDM4A lysine demethylase induces site-specific copy gain and rereplication of regions amplified in tumors. Cell. 2013;154:541-55.

194. Black JC, Atabakhsh E, Kim J, Biette KM, Van Rechem C, Ladd B, Burrowes PD, Donado C, Mattoo H, Kleinstiver BP, et al. Hypoxia drives transient site-specific copy gain and drug-resistant gene expression. Genes Dev. 2015:29:1018-31.

195. Tu S, Teng YC, Yuan C, Wu YT, Chan MY, Cheng AN, Lin PH, Juan LJ, Tsai MD. The ARID domain of the H3K4 demethylase RBP2 binds to a DNA CCGCCC motif. Nat Struct Mol Biol. 2008;15:419-21.

196. Wysocka J, Swigut T, Xiao H, Milne TA, Kwon SY, Landry J, Kauer M, Tackett AJ, Chait BT, Badenhorst P, et al. A PHD finger of NURF couples histone H3 lysine 4 trimethylation with chromatin remodelling. Nature. 2006:442:86-90.

197. Rasmussen PB, Staller P. The KDM5 family of histone demethylases as targets in oncology drug discovery. Epigenomics. 2014;6:277-86.

198. Stein J, Majores M, Rohde M, Lim S, Schneider S, Krappe E, Ellinger J, Dietel M, Stephan C, Jung K, et al. KDM5C is overexpressed in prostate cancer and is a prognostic marker for prostate-specific antigen-relapse following radical prostatectomy. Am J Pathol. 2014;184:2430-7.

199. Wang L, Mao Y, Du G, He C, Han S. Overexpression of JARID1B is associated with poor prognosis and chemotherapy resistance in epithelial ovarian cancer. Tumour Biol. 2015:36:2465-72.

200. Roesch A, Fukunaga-Kalabis M, Schmidt EC, Zabierowski SE, Brafford PA, Vultur A, Basu D, Gimotty P, Vogt T, Herlyn M. A temporarily distinct subpopulation of slow-cycling melanoma cells is required for continuous tumor growth. Cell. 2010;141:583-94.

201. Roesch A, Vultur A, Bogeski I, Wang H, Zimmermann KM, Speicher D, Korbel C, Laschke MW, Gimotty PA, Philipp SE, et al. Overcoming intrinsic multidrug resistance in melanoma by blocking the mitochondrial respiratory chain of slow-cycling JARID1B(high) cells. Cancer Cell. 2013;23:811-25.

202. Sharma SV, Lee DY, Li B, Quinlan MP, Takahashi F, Maheswaran S, McDermott U, Azizian N, Zou L, Fischbach MA, et al. A chromatin-mediated reversible drug-tolerant state in cancer cell subpopulations. Cell. 2010; 141:69-80.

203. Louis M, Rosato RR, Brault L, Osbild S, Battaglia E, Yang XH, Grant S, Bagrel D. The histone deacetylase inhibitor sodium butyrate induces breast cancer cell apoptosis through diverse cytotoxic actions including glutathione depletion and oxidative stress. Int J Oncol. 2004;25:1701-11.

204. Marsh DJ, Shah JS, Cole AJ. Histones and their modifications in ovarian cancer - drivers of disease and therapeutic targets. Front Oncol. 2014;4:144.

205. Muscolini M, Cianfrocca R, Sajeva A, Mozzetti S, Ferrandina G, Costanzo A Tuosto L. Trichostatin a up-regulates p73 and induces Bax-dependent apoptosis in cisplatin-resistant ovarian cancer cells. Mol Cancer Ther. 2008;7:1410-9

206. Qian X, LaRochelle WJ, Ara G, Wu F, Petersen KD, Thougaard A, Sehested M, Lichenstein HS, Jeffers M. Activity of PXD101, a histone deacetylase inhibitor, in preclinical ovarian cancer studies. Mol Cancer Ther. 2006;5:2086-95.

207. Dizon DS, Blessing JA, Penson RT, Drake RD, Walker JL, Johnston CM, Disilvestro PA, Fader AN. A phase II evaluation of belinostat and carboplatin in the treatment of recurrent or persistent platinum-resistant ovarian, fallopian tube, or primary peritoneal carcinoma: a gynecologic oncology group study. Gynecol Oncol. 2012;125:367-71.

208. Dizon DS, Damstrup L, Finkler NJ, Lassen U, Celano P, Glasspool R, Crowley E, Lichenstein HS, Knoblach P, Penson RT. Phase II activity of belinostat (PXD-101), carboplatin, and paclitaxel in women with previously treated ovarian cancer. Int J Gynecol Cancer. 2012;22:979-86.

209. Shen L, Cui J, Pang YX, Ma YH, Liu PS. 3-deazaneplanocin a is a promising therapeutic agent for ovarian cancer cells. Asian Pac J Cancer Prev. 2013;14: 2915-8.

210. Bitler BG, Aird KM, Garipov A, Li H, Amatangelo M, Kossenkov AV, Schultz DC, Liu Q, Shih le M, Conejo-Garcia JR, et al. Synthetic lethality by targeting 
EZH2 methyltransferase activity in ARID1A-mutated cancers. Nat Med. 2015; 21:231-8.

211. Forneris F, Battaglioli E, Mattevi A, Binda C. New roles of flavoproteins in molecular cell biology: histone demethylase LSD1 and chromatin. FEBS J. 2009;276:4304-12.

212. Hayward D, Cole PA. LSD1 histone demethylase assays and inhibition. Methods Enzymol. 2016;573:261-78.

213. Feng $S$, Jin Y, Cui M, Zheng J. Lysine-specific demethylase 1 (LSD1) inhibitor S2101 induces autophagy via the AKT/mTOR pathway in SKOV3 ovarian Cancer cells. Med Sci Monit. 2016;22:4742-8.

214. Singh AK, Chandra N, Bapat SA. Evaluation of epigenetic drug targeting of Heterogenous tumor cell fractions using potential biomarkers of response in ovarian Cancer. Clin Cancer Res. 2015;21:5151-63.

215. Jones SF, Bendell JC, Infante JR, Spigel DR, Thompson DS, Yardley DA, Greco FA, Murphy PB, Burris HA 3rd. A phase I study of panobinostat in combination with gemcitabine in the treatment of solid tumors. Clin Adv Hematol Oncol. 2011;9:225-30.

216. Chao H, Wang L, Hao J, Ni J, Chang L, Graham PH, Kearsley JH, Li Y. Low dose histone deacetylase inhibitor, LBH589, potentiates anticancer effect of docetaxel in epithelial ovarian cancer via PI3K/Akt pathway in vitro. Cancer Lett. 2013;329:17-26.

217. Tang HM, Kuay KT, Koh PF, Asad M, Tan TZ, Chung VY, Lee SC, Thiery JP, Huang RJ. An epithelial marker promoter induction screen identifies histone deacetylase inhibitors to restore epithelial differentiation and abolishes anchorage independence growth in cancers. Cell Death Discov. 2016;2:16041.

218. Aguilar-Gallardo C, Rutledge EC, Martinez-Arroyo AM, Hidalgo JJ, Domingo S, Simon C. Overcoming challenges of ovarian cancer stem cells: novel therapeutic approaches. Stem Cell Rev. 2012;8:994-1010.

Ready to submit your research? Choose BMC and benefit from:

- fast, convenient online submission

- thorough peer review by experienced researchers in your field

- rapid publication on acceptance

- support for research data, including large and complex data types

- gold Open Access which fosters wider collaboration and increased citations

- maximum visibility for your research: over $100 \mathrm{M}$ website views per year

At $\mathrm{BMC}$, research is always in progress.

Learn more biomedcentral.com/submissions 